\title{
1 Virtual strike and dip - Advancing inclusive and accessible field geology
} 2

3 Natalie Bursztyn ${ }^{1}$, Pejman Sajjadi ${ }^{2,3}$, Hannah Riegel ${ }^{4}$, Jiawei Huang ${ }^{2,3}$, Jan Oliver Wallgrün ${ }^{3}$, 4 Jiayan Zhao ${ }^{2,3}$, Bart Masters ${ }^{3}$, Alexander Klippel ${ }^{2,3}$

5 8

$9 \quad{ }^{2}$ Department of Geography, The Pennsylvania State University, Walker Building, 302 N Burrowes

10 Street, University Park, PA 16802, USA

11

$15{ }^{4}$ Department of Geological and Environmental Sciences, Appalachian State University, 033

16 Rankin Science West, Boone, NC 28608, USA 


\section{ABSTRACT}

Accessibility and inclusivity in field geology have become increasingly important issues to address in geoscience education and have long been set aside due to the tradition of field geology and the laborious task of making it inclusive to all. Although a popular saying among geologists is "the best geologists see the most rocks", field trips cost money, time, and are only accessible for those who are physically able to stay outside long hours. With the availability of 3D block diagrams, an onslaught of virtual learning environments is becoming increasingly viable. Strike and dip is at the core of any field geologist's education and career; learning and practicing these skills is fundamental to making geologic maps and understanding the regional geology of an area. In this paper, we present the Strike and Dip virtual tool $(\mathrm{SaD})$ with the objective of teaching the principles of strike and dip for geologic mapping to introductory geology students.

31 We embedded the $\mathrm{SaD}$ tool into an introductory geology course and recruited 147 students to 32 participate in the study. Participants completed two maps using the $\mathrm{SaD}$ tool and reported on their 33 experiences through a questionnaire. The $\mathrm{SaD}$ tool was overall perceived positively by students. 34 Furthermore, some individual differences among students proved to be important contributing 35 factors to their experiences and subjective assessments of learning. When controlling for participants' past experience with similar software, our results indicate that students highly familiar with navigating geographical software perceived the virtual environment of the tool to be significantly more realistic and easier to use compared to those with lower levels of familiarity. Our results are corroborated by a qualitative assessment of participants' feedback to two openended questions, highlighting both the overall effectiveness of the SaD tool, and the effect of geographical software familiarity on measures of experience and learning. 


\section{INTRODUCTION}

\section{$45 \quad 1.1$ The "field" environment: real, virtual, and implementation for remote learning}

46 The field may be the single most prominent element defining geosciences. Processes relevant to

47 Earth sciences happen in the field, and their phenomenological traces are observable in that

48 physical space. Thus, fieldwork and the educational components of field trips and field camps are

49 frequently held in the highest regard (Orion and Hofstein, 1994; Elkins and Elkins, 2007; Pyle,

50 2009; Semken et al., 2018). Fieldwork remains a graduation requirement for most geoscience

51 programs despite increasing concerns over it being inaccessible to many students, predominantly

52 from underrepresented groups, as a result of financial, cultural, physical, and safety barriers.

54 Frequently, physical locations are hard to reach, or they may be impossible, dangerous, or too 55 expensive to access (e.g., the location is on a different continent, in a restricted area, or only existed 56 in the past) (Dolphin et al. 2019; Mead et al. 2019; Klippel et al. 2019), or from the spring of 2020 57 to at least into the summer of 2021, physical field experiences are hindered by the global COVID5819 pandemic. But even without COVID-19, field experiences have been receiving a more critical examination. To name some of the prominent issues: recent studies have shown that the field experience is not inclusive and may be hindering retention and diversity within geoscience undergraduate programs (Hall et al., 2004; Giles et al., 2020; Morales et al., 2020). Field trips pose troubling accessibility issues excluding students with disabilities but also students who cannot afford to participate due to time or financial constraints. Field work is further challenged by an increasing awareness of harassment that is happening in the field, which is often targeting women and minority students and faculty who do not conform to the stereotypical mainstream conceptions of fieldwork, that is, it is a white, male-dominated domain. Marín-Spiotta et al. (2020) call out this issue, comparing it to the Vegas Rule, criticizing the understanding that "what happens in the field, stays in the field".

In contrast, virtual field trips can allow instructors to expose students to widely accessible, relevant, and authentic learning experiences independent of time and space (e.g. Stumpf et al.,

72 2008; Bursztyn et al., 2017; Mead et al. 2019; Klippel et al. 2020). Leveraging increasingly 
student engagement (Witmer and Singer, 1998; IJsselsteijn and Riva, 2003) and efforts to integrate emerging technology into the classroom to improve undergraduate success in introductory geoscience courses have further demonstrated the importance of experiential learning exemplified best by field trips (Cunningham and Lansiquot, 2019; Dolphin et al., 2019; Lansiquot and MacDonald, 2019; Moysey and Lazar, 2019). While there is some positive evidence that compares actual and virtual field trips (e.g., Klippel et al. 2019, Marshall et al. under review), there are strongly held beliefs that nothing can replace the actual field experience (numerous personal communications). Considering fieldwork without the field (i.e. in a virtual environment) is a challenging concept for Earth science educators. Consequently, virtual and remote learning in the geosciences has remained a niche product belittled by many "real" geoscientists. It required the COVID-19 pandemic to change minds and to explore remote learning opportunities for placebased education at scale and across disciplines. We have seen a dramatic influx of efforts (e.g. numerous NAGT Workshops; Earth Educators Rendezvous, 2020) and papers since 2020 that detail the creative ways a community, deprived of their traditional educational methods, has responded to distancing constraints and travel bans (e.g., Andrews et al., 2020; Bethune, 2020; Madon, 2020; Rotzein et al., 2020; Sajjadi et al. 2020; Tibaldi et al., 2020, Rotzein et al., 2021; Whitmeyer and Dordevic, 2021).

In light of the new openness to virtual experiences, it is essential to critically look at the opportunities (i.e., breaking down long standing barriers of accessibility and inclusion) and challenges that remote learning offers to Earth educators. To establish remote learning opportunities in geoscience education, we need tools as well as empirical studies that explore the opportunities, the challenges, and the feasibility of virtual learning experiences. Many studies remain anecdotal (e.g., Marshall et al., under review) but it is time to establish research frameworks and to connect place-based education with established assessments and practices in virtual and immersive learning (Klippel et al. 2020; Petersen et al. 2020). Immersive virtual reality (iVR) is inherently a three-dimensional (3D), spatial medium (Maceachren and Brewer, 2004) and therefore offers a natural interface to all representations of data that, too, are three-dimensional in nature. However, in the time of the COVID-19 pandemic, the infrastructure to equip every student implementation of massive remote learning and abiding by physical distancing restrictions. 
105 Though our research goals are ultimately to address the advancement of the science of immersive experiences, we seized the opportunity to conduct an exploratory study with a web-based desktop virtual environment.

Virtual environments, immersive or desktop-based, allow for creating realistic and flexible

110 experiences for (virtual) field trips and the learning activities (e.g., measuring geologic structures

111 and building mental models of spatial orientation and scale of landscape features) that are essential

112 to practice on these field trips. Examining digital twins of outcrops through magnification,

113 collecting samples, or measuring the stratigraphy are, with recent technological advances,

114 straightforward to realize virtually. Over the last four years we and others have been building this

115 capacity through combining efficient data collection in the form of $360^{\circ}$ images, high resolution

116 images, virtual outcrop models, and simple measuring tools. What we identified as missing are

117 more complex geological tools and pedagogies for the application and practice of concepts such

118 as strike and dip. Strike and dip measurements and rock identification are the fundamental aspects

119 of any geologic map. Taking and interpreting such field measurements both require physical

120 practice and are fundamentally essential for geoscience education, but are generally not covered

121 extensively in virtual environments (see eRock; Cawood and Bond, 2018 for exceptions). Strike

122 and dip measurements allow students and professionals alike to interpret structures in the Earth's

123 crust and reconstruct deformed regional areas. It is through strike and dip that a geologist understands the regional geology from deposition to deformation.

\subsection{Why field geology? Spatial reasoning in the geosciences}

127 Students in the geosciences are frequently required to reason about objects or features that occur

128 at spatial scales too large or small to be directly observed (Gagnier et al., 2017) or hidden from

129 view (Shipley et al., 2013; Ormand et al., 2014; Almquist et al., 2018; Zhao and Klippel, 2019;

130 Atit et al., 2020). As a result, faculty frequently describe students' difficulty with spatial

131 visualization as one of the barriers to success in the geosciences (e.g. Barab and Dede, 2007; Titus

132 and Horsman, 2009; Atit et al., 2020). In particular, spatial visualization is critical to success in

133 courses such as sedimentology and stratigraphy, structural geology, and field techniques (Gagnier

134 et al., 2017). Tectonic and sedimentary processes usually form geo-spatially predictable features,

135 deducible from patterns observed in surface data when one is capable of visualizing the 3D 
136 geometry (Alles and Riggs, 2011). Students who possess the spatial visualization abilities necessary to succeed in these courses are also more likely to continue in the geosciences (Titus and Horsman, 2009).

The development of geological reasoning skills can be scaffolded by introducing students to a sequence of exercises starting with prototypical, accessible, and understandable physical locations, and also by introducing more experiential practice opportunities at the lower-level prior to the more challenging applications found in subsequent upper-level geoscience courses. In many postsecondary institutions, the concept of strike and dip as geological measurements is introduced in an introductory physical geology course. Later, students practice taking these measurements extensively in a field methods course, apply these methods through different lenses of geologic interpretation in subsequent focus courses, and conclude with a capstone summer field course:

148 Field Camp. Visualizing the 3D forms and structures of our planet is a critical skill for the geosciences, and the foundation of this skill lies in a solid understanding of geological maps and strike and dip measurements.

\subsection{A place for virtual and immersive technologies in place-based learning}

Place-based learning, such as field trips, combines the practices found in problem-based learning and experiential learning to foster a sense of place that generates an authentic learning environment, something valued across disciplines from social to physical sciences. Virtual environments, and especially immersive virtual environments, allow for creating learning environments grounded in the same learning theories and pedagogies as place-based education. Associated theories are discussed from different angles such as discovery, inquiry, and problembased learning as well as experiential learning (Kolb, 2014). The focus of this article is not on learning theories and as such we are not providing an in-depth discussion of the different approaches. Similarities of these approaches are grounded in a constructivist perspective on learning (Winn, 1993; Dalgarno, 2002) building on the power of contextualizing learning through integrating prior knowledge and experience in addition to the context in which the content is

164 embedded. Bangera and Bronwell (2014) found that benefits of these approaches include that they 165 may offer a more effective and accessible starting point for students, including minority, low166 income, and first-generation college students and can provide students with a greater ability to use 
167 scientific thinking in other aspects of their lives. These approaches, and in particular discovery-

168 based learning, have also been found to be key to successful STEM education (PCAST, 2012).

170 What role can virtual and immersive technologies play in discovery-based courses and fostering 171 equity and access to STEM education such as geoscience field trips? The theoretical basis for the 172 transformative nature, especially of immersive technologies for education, is rapidly growing 173 (Dede, 2009; O'Connor and Domingo, 2017; Liu et al., 2020; Parong and Mayer, 2020; Wu et al., 174 2020). Characteristics of virtual and immersive technologies lend themselves to realize place175 based learning (Semken et al., 2018), experiential and embodied learning (Johnson-Glenberg 176 2018) as well as designing environments for discovery-based learning. Placing learners into the real-world with a specific problem that is relevant to a location provides a more direct connection of key learning points that students can understand and use to become more engaged (Powers, 2004). Designing virtual environments in which students' learning activities are scaffolded by exercises and instruction is at the core of discovery-based learning (McComas, 2014). Geological processes can sometimes be difficult to visualize during field trips due to vast spatial and time scales - this is one area in the discipline that iVR can offer a distinct advantage. The blending of place-based and discovery-based learning, especially in immersive, virtual environments allows for the "perceptual blending of the real and the virtual world with its place-based authenticity" to enable better learning experiences (Barab and Dede, 2007, p. 2). The geosciences have long been either explicitly or implicitly using experiential, place-based exercises to foster discovery-based learning in their curriculum through, for example, field trips (Semken et al., 2018; Atit et al., 2020).

188 Entering the 2020 Field Camp season, a crucial component of most traditional geoscience 189 programs, instructors and students were faced with limited options: no field camp, limited and socially distanced field camp, or virtual field camp. Here it is pertinent to channel the virtuality momentum into constructive, critical, and empirically-grounded discussions of the future and utility of VR for geoscience education. It is important to note that virtual and immersive virtual experiences cannot only be designed to mimic actual field experience but that they offer opportunities beyond physical reality such as reacting to the learner in real-time (Lopes and 
197 This paper presents a virtual Strike and Dip tool $(\mathrm{SaD})$ in a web-based desktop virtual reality (dVR) environment. In addition to posing many challenges, the COVID-19 pandemic induced transition to primarily online teaching also presented geoscience educators with a new opportunity to improve introductory field-mapping instruction to be more inclusive if we are able to recreate strike and dip lab experiences through virtual environments. $\mathrm{SaD}$ is an interactive experience created for the purpose of guiding students to think spatially for critical geological applications by taking strike and dip measurements from 3D models of geological structures. The $\mathrm{SaD}$ tool mimics an introductory geologic mapping lab where students are taught strike and dip measurements using a set of angled boards with accompanying rock samples staged around a classroom (or open space) to reveal an imagined geologic structure. We have replicated this experience and traditional pedagogies in the virtual world with $\mathrm{SaD}$ and its series of digital planes and corresponding virtual rock samples. With this tool, students can learn what strike and dip measurements are, learn the basics of field mapping using strike and dip, as well as practice taking measurements using a variety of geological structure types. The $\mathrm{SaD}$ tool mimics geoscience place-based learning experiences and combines them with the flexibility and scalability of dVR. A small-scale pilot assessment (eleven participants) using the $\mathrm{dVR}$ SaD interface and an accompanying mapping assignment was completed in Fall 2020 and presented at a workshop (Bursztyn et al., 2021). Building on the pilot study we improved the design iteratively and rolled out $\mathrm{SaD}$ as a large-scale study in a 250 student introductory geoscience class. We present here a more in-depth discussion of $\mathrm{SaD}$, the newly conducted empirical evaluation and analysis, a critical discussion of results showing important considerations for the future of virtual geosciences, and our vision for future $\mathrm{SaD}$ and virtual geoscience toolkit developments.

\section{METHODS}

\subsection{The Strike and Dip tool}

The representation of 3D geologic structures in 2D form requires several standard map notations, the most important of which are strike and dip measurements. New learners are typically introduced to taking strike and dip measurements using the "right hand rule" (RHR) convention. There are a few variations of the RHR, but a commonly used one (and the one used in this study) is as follows: hold the right hand flat, with the palm down on the planar geologic feature, thumb 
extended at $90^{\circ}$ degrees to fingers, and fingers pointing down dip (Fig. 1). Strike and dip is often a challenging concept to teach to new learners of geology in the best of times, but the COVID-19 pandemic presented geoscience educators with a new challenge: removing the in-person field trip instruction that provides guided practice in taking strike and dip measurements. Therefore, what were deemed the fundamental components of in-person field instruction for learning to measure geologic structures (identifying strike and dip planes and manipulating a compass to determine their orientation in space), were the primary focus of the $\mathrm{SaD}$ tool.
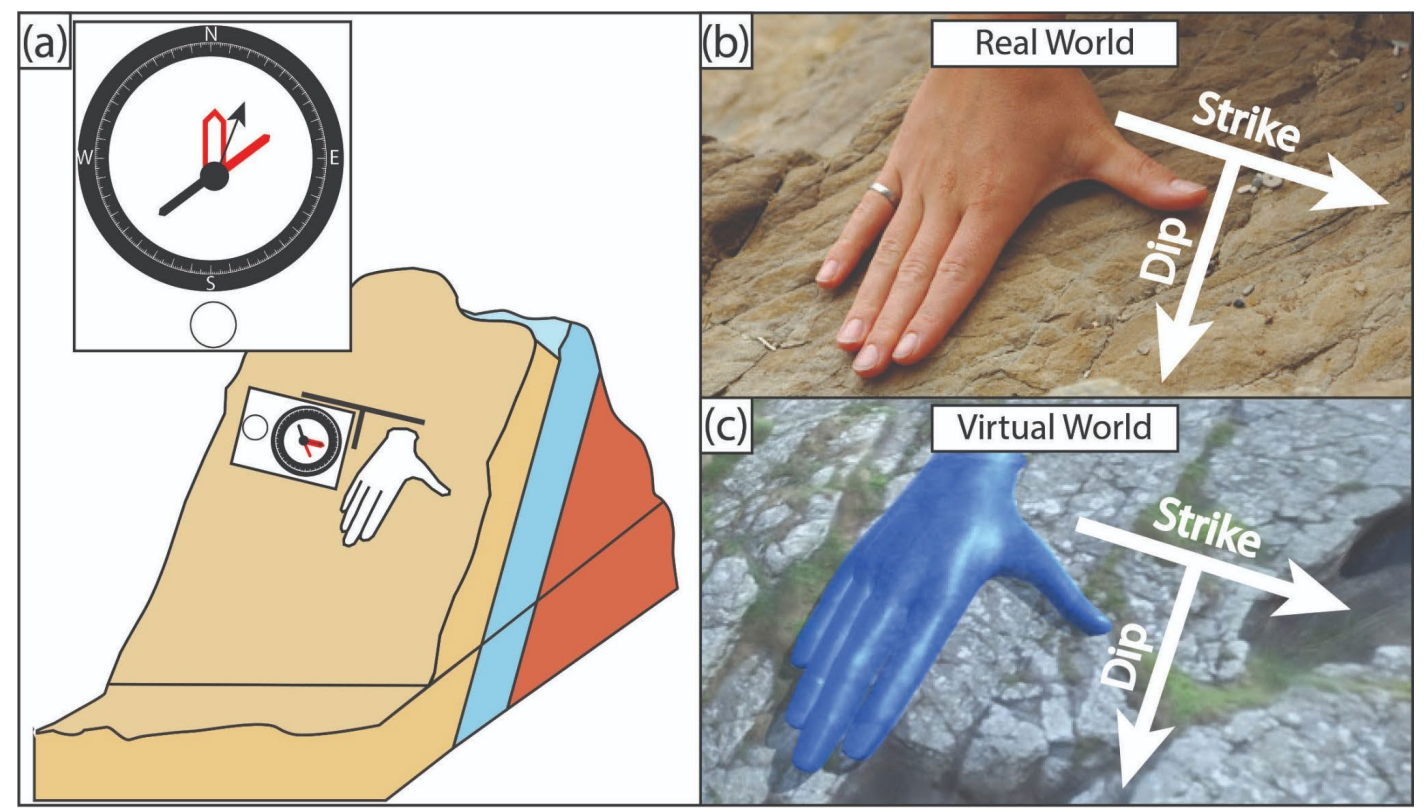

Figure 1. A schematic of how one measures strike and dip on an outcrop. (a) One measures strike and dip on the planar surface of a rock. The strike represents the line at which the planar rock surface intersects with any horizontal plane. The dip angle is the angle between that dipping surface and the horizontal plane. (b) An example of one using RHR in the real world and (c) in the $\mathrm{SaD}$ virtual field environment.

The primary components of the SaD tool are the Compass Tool and the Small Data Panel/Data Set (Fig. 2a; 2b). The strike and dip data are recorded in the tool in the All Data Sets panel (Fig. $2 b)$. Users can navigate around a $3 \mathrm{D}$ digital environment to locations where they can measure the strike and dip of various slopes (platforms or outcrops). The user can locate their position via the Mini World Map or fullscreen World Map (Fig. 2c). Once the user is positioned close to the slope 
245 they would like to measure, they orient the position and rotation of the compass tool (using the 246 compass control panel) to correspond to the strike or dip measurements. In the virtual environment 247 levels, "station locations" are specifically laid out to correspond to the assignment maps.

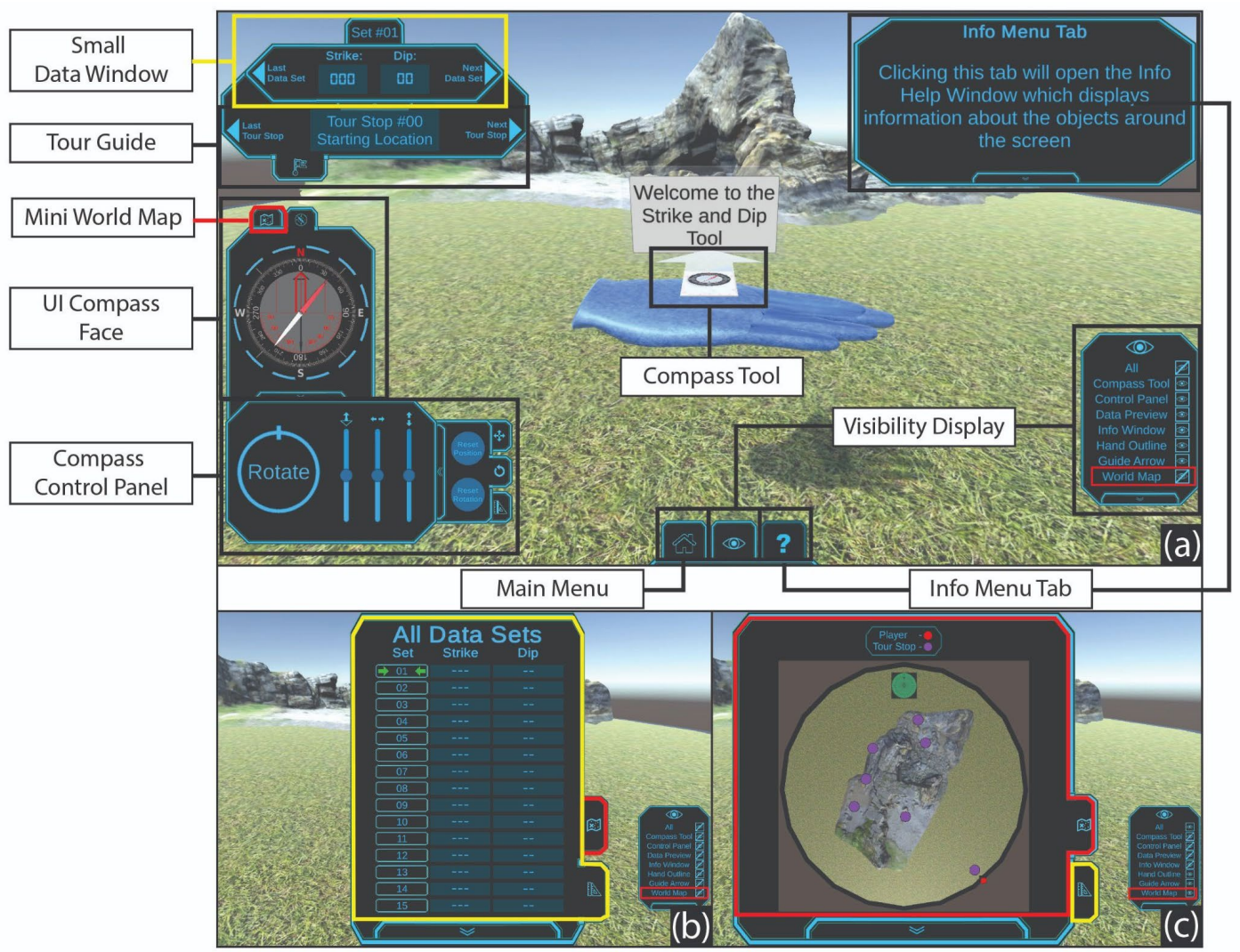

Figure 2. The SaD HUD (Heads Up Display). The HUD is composed of all the tools visible on screen throughout the program. Each tool can be toggled on/off depending on user preference. (a)

251 The main HUD displays the Small Data Window, where the user's most recent strike and dip 252 measurements are displayed. The Tour Guide allows the user to view which stop they are presently 253 located. The Mini World Map (red outline) shows the user their location in a miniature view. The 254 user may view the compass with more ease using the UI Compass Face as they are measuring the 255 orientation of the rock with the Compass Tool. The Compass Control Panel is used to position the 256 compass on the outcrop/board to measure orientation. The Main Menu display allows the user to 257 adjust the speed at which they/the compass move, the level they are on, and more personalization features. The Info Menu Tab gives brief information about each tool when the user hovers over 
259 them. Finally, the Visibility Display allows the user to toggle on/off each tool. (b) If the user wishes 260 to view their entire strike and dip log, they can click on the triangle protractor icon (yellow outline).

261 (b) The user can also click on the World Map (red outline) to view their location in the environment 262 at full screen.

264 There are four different setting levels within the $\mathrm{SaD}$ tool; from least to most challenging they are:

265 bumper cubes, bumper rocks, cubes, and rocks. The two cubes levels have field stations set up 266 within the virtual environment as rectangular planes with a virtual hand sample rock floating above 267 (Fig. 3a). The cubes levels have very obvious planar surfaces for taking strike and dip 268 measurements. The two rocks levels have their field stations set up with rectangular planes draped 269 with rock "skins" that give an appearance closer to an outcrop (Fig. 3b). Depending on the 270 complexity of the rock texture of the "skin", the planar surfaces within the rocks level 271 environments are more challenging to precisely identify. The two bumper levels have an algorithm 272 that flags the strike and dip measurements in red if they are greater than $10^{\circ}$ and $5^{\circ}$ off, respectively. 273 These flags enable self-correction by the students and facilitate only recording correct 274 measurements in the data display panel. 


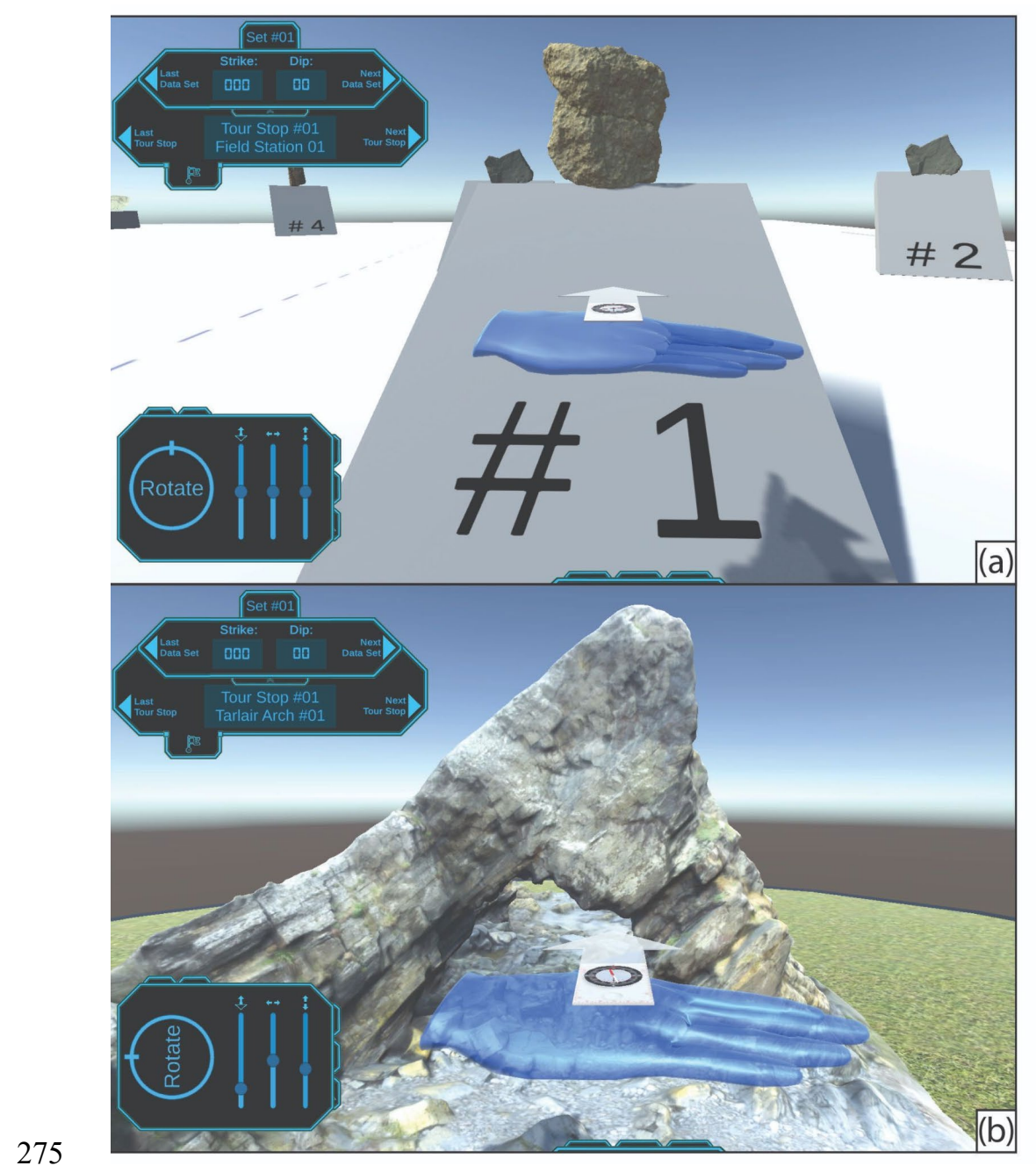

Figure 3. The two main settings: cubes and rocks. Each may be used with the bumper prefix to allow the user an error-flagging buffer when measuring platform/outcrop orientation $\left(+/-10^{\circ}\right.$ strike, $5^{\circ}$ dip). (a) shows the level cubes which replicates the classroom beginner technique of using a platform to practice taking strike and dip measurements. (b) An example of the rocks level, which features 3D outcrops.

\subsubsection{Participants}

A total of 147 undergraduate students (with an average age of 19.73) participated in this study. Out of this population, 98 students self-identified as male, 44 as female, three as other, and two 
285 preferred not to answer. All students were recruited from an introductory geoscience class (Geosc 001 - Physical Geology) at The Pennsylvania State University in the Fall 2020 semester. This class was chosen for the introductory nature of material taught including the strike and dip content already in the course curriculum. The $\mathrm{SaD}$ experience was embedded in this course as a laboratory assignment and students were awarded course credit for their participation. In essence, the laboratory was conducted in a context equivalent to the traditional face-to-face environment.

291

\subsubsection{Procedure}

293 The lab exercise was administered with the help of teaching assistants (TAs). Before the related 294 laboratory lecture, students were assigned homework readings. During the lecture they were 295 presented the standard introductory material on geologic maps and mapping, such as how to 296 interpret the geologic rule of v's, measuring and plotting strike and dip on a map, drawing contacts, 297 and constructing basic cross-sections. Earlier in the semester students completed a geologic 298 mapping exercise from their lab workbooks for which they were provided strike and dip 299 measurements. This lab exercise was graded and returned to the students prior to their introduction 300 to the $\mathrm{SaD}$ tool. At the beginning of the $\mathrm{SaD}$ lab, students were shown an introductory video 301 tutorial demonstrating how to access and utilize the $\mathrm{SaD}$ tool through an online dVR environment.

302 Navigation between "field stations" within the environment using arrow keys and/or mouse, proper 303 hand placement for right hand rule, measurement of strike and dip, as well as using the mini map 304 feature are all demonstrated within this tutorial video. TAs provided additional office hours after 305 the lab session and online video resources (which included a longer comprehensive tutorial video 306 and written instructions for the $\mathrm{SaD}$ tool as well as a video tutorial on the basics of geologic 307 mapping and drawing a cross-section). Participants in this study used the SaD tool at the beginner 308 (least challenging) bumper cubes level.

310 The lab exercise was completed in a single 3-hour lab session and consisted of two parts, both 311 tasking the students with gathering information (strike and dip, rock descriptions) with which to 312 compile a geologic map, legend, cross section, and interpretation of geologic events that formed 313 the area. Students were given blank base maps and fill-in-the-blank field notes to complete as they 314 worked in the virtual environment. This aspect of the assignment tasked the students with 
315 transcribing the data as they would in the real world and practice active mapping. Students were

316 also provided with the rock identifications for the map areas to reduce the number of tasks they

317 had to complete in their single lab session. The first mapping activity (Map 1) of the assignment

318 was an optional "practice" map with five rock types, six field stations, and relatively simple

319 geologic relationships to interpret (Fig. 4). The second mapping activity of the assignment (Map

320 2) was classified as the "real" map with 15 field stations and slightly more complex geologic

321 relationships; this is the map that was evaluated for their grade in this lab assignment. Assessment

322 of the lab exercise included evaluation of 1) the map itself, 2) the field notes, 3) the cross-section,

323 4) the explanation, and 5) the interpretation of geologic events that formed the area (Fig. 4).
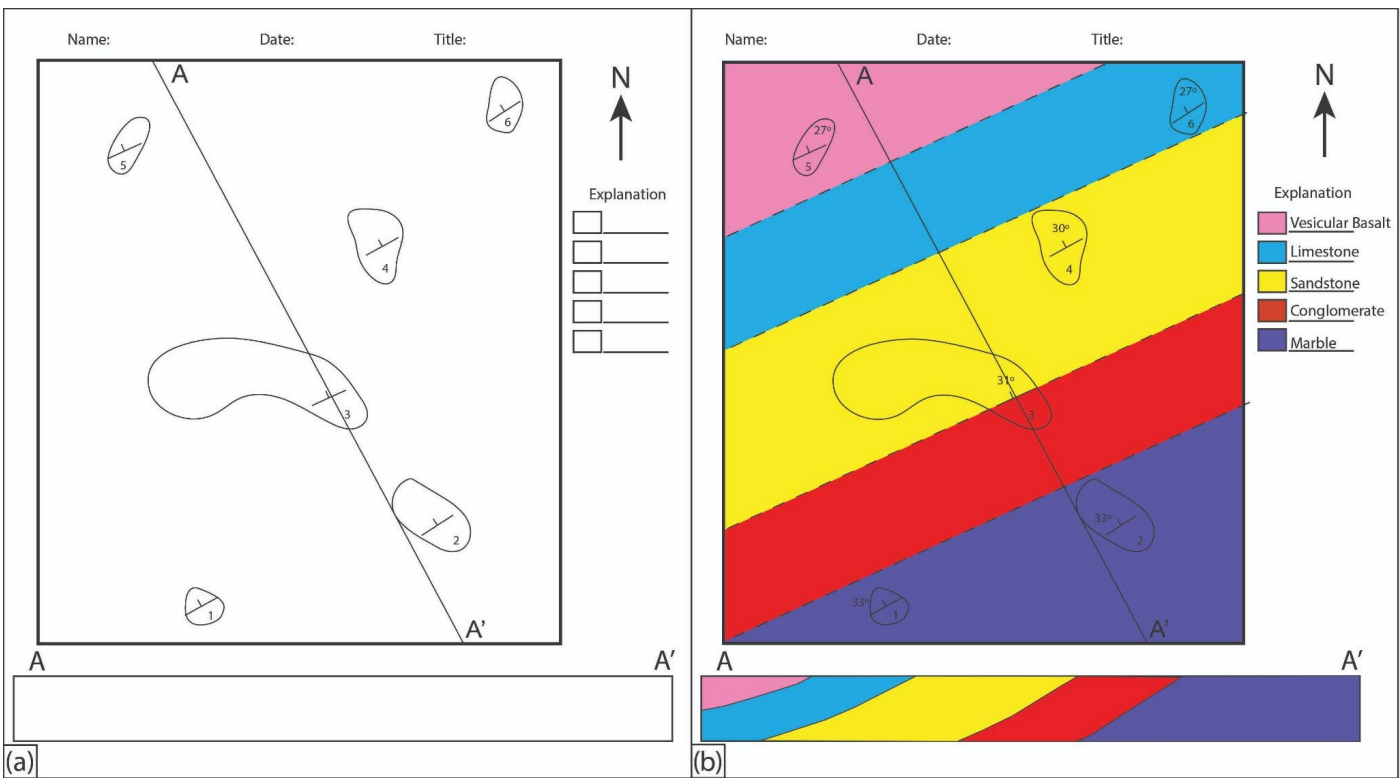

Figure 4. The before and after examples of Map 1. (a) Students are initially given a blank map with space to fill in the explanation and cross-section. Students are expected to fill in field notes and interpretation of geologic events on a separate piece of paper. (b) A completed map and accompanying cross-section. 


\subsection{Assessment measures and analyses}

333 The experiences and learning of the participants were assessed using self-reported questionnaires

334 (Appendix A). All of the questionnaire items are from established and validated instruments 335 (summarized and connaturalized by Lee et al., 2010 and Klingenberg, 2020). As part of the 336 demographic information, participants were asked to report on their age, gender, major and minor 337 fields of study, and year of study. Furthermore, participants were asked to report on their 338 familiarity with navigating geographical software such as ArcGIS, as well as their familiarity with 339 playing computer games.

340

\subsubsection{Quantitative assessment and analyses}

After interacting with the $\mathrm{SaD}$ tool, the experiences (learning and general) of the participants were measured in light of representational fidelity, immediacy of control, perceived usefulness, perceived ease of use, motivation, control and active learning, reflective thinking, perceived learning effectiveness, satisfaction, and self-efficacy (Table 1, see also Appendix A for the full question list). All constructs were measured on a scale of 1 to 5 and individual items were averaged and collapsed into the final construct score.

In order to maintain an unbiased distribution into the low/high categories, cases where a participant scored exactly the same as the median ( 3 for geographical software familiarity, and 4 for gaming familiarity) were excluded. Using this approach 53 participants were identified belonging to the low-Software Familiarity category, 41 to high-Software Familiarity, 47 to low-Gaming Familiarity, and 66 to high-Gaming Familiarity. The experience and learning metrics of participants were compared based on these categories using the independent samples t-test or, alternatively, Mann-Whitney $\mathrm{U}$ test in case of non-normal distribution.

In addition to geographical software and gaming familiarity, we also explored the effect of gender on the experiences and learning of participants. As such, the experiences and learning metrics of 98 male participants were compared with 44 female participants. Two-way ANOVAs were conducted to explore the interaction effect between geographical software/gaming familiarity and 

performed using IBM SPSS Statistics 22.

Table 1. Metrics from participant questionnaire and their respective explanations

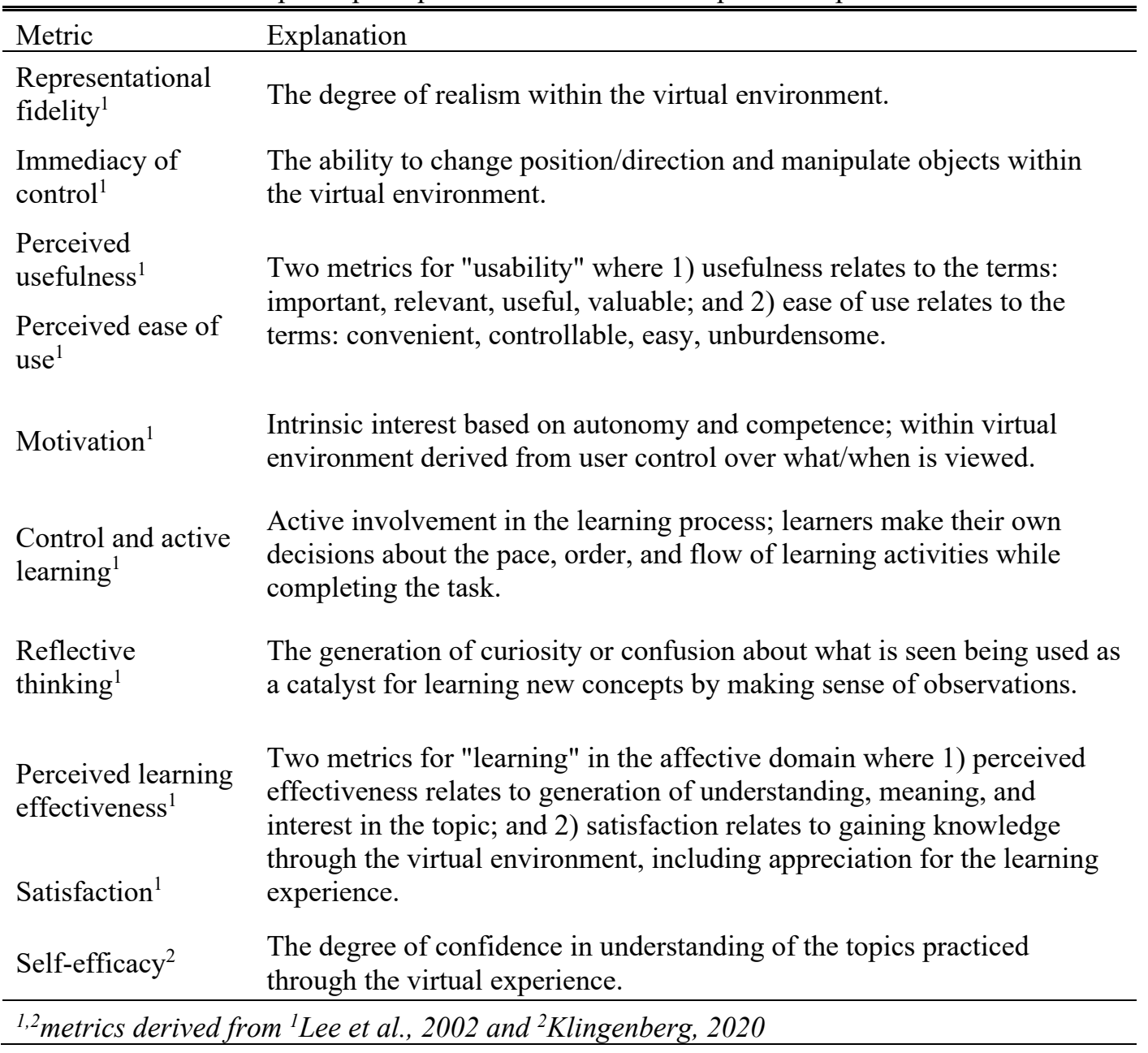

\subsubsection{Qualitative assessment and analyses}

365 Within the survey, two open-ended questions were asked from the participants about their 366 experiences with the $\mathrm{SaD}$ tool:

367 1) "How was your learning experience using this tool? Describe how you felt about practicing 368 geologic mapping in a virtual environment." 
369 2) "How did your experience using the strike and dip tool change between the first and second mapping activities? Explain within the context of the technology (ease of use, functionality, etc.)"

371 Combined with the quantitative analyses, qualitative analyses provide deeper insights into how the

$372 \mathrm{SaD}$ tool was perceived by the participants. Based on the structured content analysis approach 373 proposed by Schreier (2012), two independent coders examined the responses of participants and 374 inductively generated codes that would capture their content. The coders reached agreement by 375 grouping and rearranging the codes into the final schemas (one for each question) based on the 376 most frequent codes. Inter-rater reliability tests based on Cohen's Kappa were also conducted for 377 the finalized results. To further understand these results, we examined the associations between 378 geographical software familiarity and gaming familiarity groupings (high/low) and each of the 379 codes using a chi-square test of independence and a post-hoc test with Bonferroni correction 380 (resulting in an adjusted alpha of 0.0125).

\section{RESULTS}

\subsection{Quantitative analysis}

383 We first looked at the scores for the different measured metrics (Table 1) averaged over all 384 participants to analyze the overall assessment of the SaD tool. The results summarized in Table 2 385 show slightly above-average scores for the representational fidelity and motivation metrics, and 386 well-above-average scores for immediacy of control, perceived usefulness, perceived ease of use, 387 control and active learning, reflective thinking, perceived learning effectiveness, satisfaction, and 388 self-efficacy. These scores indicate a positive overall evaluation of the $\mathrm{SaD}$ tool, implying that it succeeded in eliciting a good experience for users, and therefore can be considered an effective

390 learning instrument.

391 As a second step, we were interested in how the experience with the $\mathrm{SaD}$ tool was impacted by 392 individual differences between the participants related to past exposure to geographical software 393 and video games. The sampled population reported a slightly above-average score for familiarity 394 with navigating geographical software $(\mathrm{M}=2.86, \mathrm{SD}=1.25)$, and a well-above average score for familiarity with gaming $(\mathrm{M}=3.91, \mathrm{SD}=1.23)$. The results from the analyses comparing the survey 
Tables 3 and 4 that follow.

Table 2. 5-point scale survey results

\begin{tabular}{lll}
\hline \hline Metric & Mean & S.D. \\
\hline Representational fidelity & 2.96 & 0.99 \\
Immediacy of control & 3.36 & 1.02 \\
Perceived usefulness & 3.25 & 0.99 \\
Perceived ease of use & 3.28 & 0.8 \\
Motivation & 2.95 & 0.83 \\
Control and active learning & 3.33 & 0.91 \\
Reflective thinking & 3.16 & 0.97 \\
Perceived learning effectiveness & 3.11 & 0.92 \\
Satisfaction & 3.12 & 0.92 \\
Self-efficacy & 3.37 & 0.84 \\
\hline
\end{tabular}

398

399 Our results indicate statistically significant differences (by a combination of independent samples

400 t-tests and the Mann-Whitney test in the case of non-normal distribution) for almost all the metrics

401 in the general and learning experiences of students grouped by low and high software familiarity.

402 For representational fidelity, scores of the high software familiarity group were higher than those

403 in the low software familiarity group $(\mathrm{M}=3.46, \mathrm{SD}=0.95$ and $\mathrm{M}=2.59, \mathrm{SD}=0.92$, respectively; $\mathrm{t}(92)$

$404=4.461, \mathrm{p}<0.001)$. For immediacy of control, scores in the high familiarity group were higher

405 than in the low familiarity group $(\mathrm{M}=3.7, \mathrm{SD}=0.89$ and $\mathrm{M}=3.21, \mathrm{SD}=1.17$, respectively; $\mathrm{t}(92)=$

$4062.188, \mathrm{p}=0.026$ ). For perceived usefulness, scores in the high familiarity group were higher than

407 in the low familiarity group $(\mathrm{M}=3.56, \mathrm{SD}=1$ and $\mathrm{M}=3.01, \mathrm{SD}=1.07$, respectively; $\mathrm{t}(92)=2.536, \mathrm{p}$

$408=0.013)$. For perceived ease of use, scores in the high familiarity group were higher than in the

409 low familiarity group $\left(\mathrm{Mdn}=3.75\right.$ and $\mathrm{Mdn}=2.75$, respectively; $\mathrm{U}\left(\mathrm{N}_{\mathrm{low}}=53, \mathrm{~N}_{\text {high }}=41\right)=554.500$,

$410 \mathrm{z}=-3.979, \mathrm{p}<0.001)$. For perceived learning effectiveness, scores in the high familiarity group

411 were higher than in the low familiarity group $(\mathrm{M}=3.45, \mathrm{SD}=0.82$ and $\mathrm{M}=2.95, \mathrm{SD}=0.95$,

412 respectively; $\mathrm{t}(92)=2.728, \mathrm{p}=0.008)$. For satisfaction, scores in the high familiarity group were

413 higher than in the low familiarity group $(\mathrm{M}=3.4, \mathrm{SD}=0.92$ and $\mathrm{M}=2.9, \mathrm{SD}=0.97$, respectively; $\mathrm{t}(92)$

$414=2.570, \mathrm{p}=0.012$ ). Lastly, scores for self-efficacy were greater in the high familiarity group than 
415 in the low familiarity group $(\mathrm{M}=3.64, \mathrm{SD}=0.83$ and $\mathrm{M}=3.16, \mathrm{SD}=0.89$, respectively; $\mathrm{t}(91)=2.651$, $416 \mathrm{p}=0.01)$. For a complete reporting of these results refer to Table 3.

Table 3. Results of independent samples t-test comparing students grouped by software familiarity

\begin{tabular}{|c|c|c|c|c|c|}
\hline Metric & $\begin{array}{l}\text { Software } \\
\text { Familiarity }\end{array}$ & $\mathrm{N}$ & Mean & Std. Dev. & $P$ \\
\hline \multirow{3}{*}{$\begin{array}{l}\text { Representational } \\
\text { fidelity }\end{array}$} & Low & 53 & 2.59 & 0.92 & \multirow{3}{*}{$<0.001^{* *}$} \\
\hline & High & 41 & 3.46 & 0.95 & \\
\hline & Total & 94 & 2.97 & 1.02 & \\
\hline \multirow{3}{*}{ Immediacy of control } & Low & 53 & 3.21 & 1.17 & \multirow{3}{*}{$0.026^{*}$} \\
\hline & High & 41 & 3.7 & 0.89 & \\
\hline & Total & 94 & 3.42 & 1.08 & \\
\hline \multirow{3}{*}{ Perceived usefulness } & Low & 53 & 3.01 & 1.07 & \multirow{3}{*}{$0.013 *$} \\
\hline & High & 41 & 3.56 & 1 & \\
\hline & Total & 94 & 3.25 & 1.07 & \\
\hline \multirow{3}{*}{ Perceived ease of use } & Low & 52 & 2.98 & 0.76 & \multirow{3}{*}{$<0.001^{* *}$} \\
\hline & High & 41 & 3.68 & 0.77 & \\
\hline & Total & 93 & 3.29 & 0.84 & \\
\hline \multirow{3}{*}{ Motivation } & Low & 53 & 2.87 & 0.88 & \multirow{3}{*}{0.3} \\
\hline & High & 41 & 3 & 0.89 & \\
\hline & Total & 94 & 2.93 & 0.88 & \\
\hline \multirow{3}{*}{$\begin{array}{l}\text { Control and active } \\
\text { learning }\end{array}$} & Low & 53 & 3.2 & 0.97 & \multirow{3}{*}{0.1} \\
\hline & High & 41 & 3.56 & 0.86 & \\
\hline & Total & 94 & 3.36 & 0.94 & \\
\hline \multirow{3}{*}{ Reflective thinking } & Low & 53 & 3 & 0.99 & \multirow{3}{*}{0.2} \\
\hline & High & 41 & 3.33 & 0.84 & \\
\hline & Total & 94 & 3.19 & 0.94 & \\
\hline \multirow{3}{*}{$\begin{array}{l}\text { Perceived learning } \\
\text { effectiveness }\end{array}$} & Low & 53 & 2.95 & 0.95 & \multirow{3}{*}{$0.008^{* *}$} \\
\hline & High & 41 & 3.45 & 0.82 & \\
\hline & Total & 94 & 3.17 & 0.93 & \\
\hline \multirow{3}{*}{ Satisfaction } & Low & 53 & 2.9 & 0.97 & \multirow{3}{*}{$0.012 *$} \\
\hline & High & 41 & 3.4 & 0.92 & \\
\hline & Total & 94 & 3.12 & 0.97 & \\
\hline \multirow{3}{*}{ Self-efficacy } & Low & 53 & 3.16 & 0.89 & \multirow{3}{*}{$0.010^{*}$} \\
\hline & High & 40 & 3.64 & 0.83 & \\
\hline & Total & 93 & 3.37 & 0.89 & \\
\hline
\end{tabular}

${ }^{*} P<0.05 ;{ }^{*} P<0.001 ;$ italics denote metrics with non-normal distribution for which Mann-Whitney test was also used 
417 A similar trend in the results was observed for students grouped by gaming familiarity. Our results 418 indicate statistically significant differences (by a combination of independent samples t-tests and 419 the Mann-Whitney test in the case of non-normal distribution) for almost all the metrics in the 420 general and learning experiences of students grouped by low and high gaming familiarity. For 421 representational fidelity, scores of students belonging to the high gaming familiarity group were 422 higher than those in the low gaming familiarity group $(\mathrm{Mdn}=3.25$ and $\mathrm{Mdn}=3$, respectively; $\left.423 \mathrm{U}\left(\mathrm{N}_{\mathrm{low}}=47, \mathrm{~N}_{\text {tigh }}=66\right)=1167.500, \mathrm{z}=-2.266, \mathrm{p}=0.023\right)$. For immediacy of control, scores of 424 students belonging to the high gaming familiarity group were higher than in the low gaming 425 familiarity group ( $\mathrm{Mdn}=3.75$ and $\mathrm{Mdn}=3$, respectively; $\mathrm{U}\left(\mathrm{N}_{\mathrm{low}}=47, \mathrm{~N}_{\text {hizh }}=66\right)=959.000, \mathrm{z}=$ $4263.467, \mathrm{p}=0.001$ ). For perceived usefulness, scores of students belonging to the high gaming 427 familiarity group were higher than in the low gaming familiarity group $(\mathrm{M}=3.42, \mathrm{SD}=0.74$ and $428 \mathrm{M}=2.96, \mathrm{SD}=0.8$, respectively; $t(111)=2.483, p<0.05)$. For perceived ease of use, scores of 429 students belonging to the high gaming familiarity group were higher than the low gaming 430 familiarity group $(\mathrm{M}=3.42, \mathrm{SD}=0.74$ and $\mathrm{M}=2.95, \mathrm{SD}=0.8$, respectively; $t(110)=3.459, p<0.01)$. 431 For control and active learning, scores of students belonging to the high gaming familiarity group 432 were higher than the low gaming familiarity group $(\mathrm{M}=3.5, \mathrm{SD}=0.85$ and $\mathrm{M}=3.12, \mathrm{SD}=0.9$, 433 respectively; $t(111)=2.253, p<0.05)$. For perceived learning effectiveness, scores of students 434 belonging to the high gaming familiarity group were higher than the low gaming familiarity group $435\left(\mathrm{Mdn}=3.43\right.$ and $\mathrm{Mdn}=3$, respectively; $\left.\mathrm{U}\left(\mathrm{N}_{\mathrm{low}}=47, \mathrm{~N}_{\text {high }}=66\right)=1147.000, \mathrm{z}=-2.357, \mathrm{p}=0.018\right)$. 436 For satisfaction, scores of students belonging to the high gaming familiarity group were higher 437 than the low gaming familiarity group ( $\mathrm{Mdn}=3.42$ and $\mathrm{Mdn}=3$, respectively; $\mathrm{U}\left(\mathrm{N}_{\mathrm{low}}=47, \mathrm{~N}_{\text {high }}=\right.$ $43866)=1122.000, z=-2.504, p=0.012$ ). Lastly, for self-efficacy, scores of students belonging to the 439 high gaming familiarity group were higher than the low gaming familiarity group $(\mathrm{M}=3.55$, $440 \mathrm{SD}=0.78$ and $\mathrm{M}=2.86, \mathrm{SD}=0.92$, respectively; $t(110)=3.296, p<0.01)$. For a complete reporting 441 of these results refer to Table 4 .

442 With respect to gender, our results indicate that male students $(\mathrm{M}=3.48, \mathrm{SD}=0.83)$ reported 443 significantly higher scores for self-efficacy than female students $(\mathrm{M}=3.12, \mathrm{SD}=0.85), t(139)=$ $4442.329, p<0.05)$. No other significant differences for gender were shown to exist. 
Table 4. Results of independent samples t-test comparing students grouped by gaming familiarity

\begin{tabular}{|c|c|c|c|c|c|}
\hline Metric & $\begin{array}{l}\text { Gaming } \\
\text { Familiarity }\end{array}$ & $\mathrm{N}$ & Mean & Std. Dev. & $P$ \\
\hline \multirow{3}{*}{$\begin{array}{l}\text { Representational } \\
\text { fidelity }\end{array}$} & Low & 47 & 2.69 & 1.06 & \multirow{3}{*}{$0.023^{*}$} \\
\hline & High & 66 & 3.13 & 0.92 & \\
\hline & Total & 113 & 2.95 & 1 & \\
\hline \multirow{3}{*}{ Immediacy of control } & Low & 47 & 3 & 1.08 & \multirow{3}{*}{$0.001 * *$} \\
\hline & High & 66 & 3.7 & 0.86 & \\
\hline & Total & 113 & 3.4 & 1 & \\
\hline \multirow{3}{*}{ Perceived usefulness } & Low & 47 & 2.96 & 0.8 & \multirow{3}{*}{$0.015^{*}$} \\
\hline & High & 66 & 3.42 & 0.74 & \\
\hline & Total & 113 & 3.23 & 0.98 & \\
\hline \multirow{3}{*}{$\begin{array}{l}\text { Perceived ease of } \\
\text { use }\end{array}$} & Low & 47 & 2.95 & 0.8 & \multirow{3}{*}{$0.001 * *$} \\
\hline & High & 65 & 3.42 & 0.74 & \\
\hline & Total & 112 & 3.25 & 0.8 & \\
\hline \multirow{3}{*}{ Motivation } & Low & 47 & 2.77 & 0.92 & \multirow{3}{*}{0.131} \\
\hline & High & 66 & 3.03 & 0.81 & \\
\hline & Total & 113 & 2.92 & 0.86 & \\
\hline \multirow{3}{*}{$\begin{array}{l}\text { Control and active } \\
\text { learning }\end{array}$} & Low & 47 & 3.12 & 0.9 & \multirow{3}{*}{$0.027^{*}$} \\
\hline & High & 66 & 3.5 & 0.85 & \\
\hline & Total & 113 & 3.34 & 0.89 & \\
\hline \multirow{3}{*}{ Reflective thinking } & Low & 47 & 2.93 & 1.1 & \multirow{3}{*}{0.05} \\
\hline & High & 66 & 3.32 & 0.9 & \\
\hline & Total & 113 & 3.15 & 1.01 & \\
\hline \multirow{3}{*}{$\begin{array}{l}\text { Perceived learning } \\
\text { effectiveness }\end{array}$} & Low & 47 & 2.82 & 0.98 & \multirow{3}{*}{$0.018^{*}$} \\
\hline & High & 66 & 3.27 & 0.88 & \\
\hline & Total & 113 & 3.08 & 0.95 & \\
\hline \multirow{3}{*}{ Satisfaction } & Low & 47 & 2.86 & 0.92 & \multirow{3}{*}{$0.012 *$} \\
\hline & High & 66 & 3.28 & 0.89 & \\
\hline & Total & 113 & 3.1 & 0.92 & \\
\hline \multirow{3}{*}{ Self-efficacy } & Low & 47 & 3.01 & 0.91 & \multirow{3}{*}{$0.001 * *$} \\
\hline & High & 65 & 3.55 & 0.78 & \\
\hline & Total & 112 & 3.32 & 0.88 & \\
\hline
\end{tabular}

$* P<0.05 ; * * P<0.001 ;$ italics denote metrics with non-normal distribution for which Mann-Whitney test was also used 
447 Finally, we were interested in investigating the possible interactions between geographical

448 software/gaming familiarity and gender on the experience and learning metrics of participants.

449 Two-way analyses of variance (ANOVAs) were conducted for this inquiry and revealed no

450 statistically significant results.

452 Our results indicate that the individual differences among students in light of their prior familiarity

453 with navigating geographical software as well as their familiarity with gaming has a pronounced

454 effect on their experiences. The unveiled trend indicates that higher familiarity with either

455 geographical software or gaming leads to a significantly better experience with the $\mathrm{SaD}$

456 tool. Importantly, no effects of gender or significant interactions between software/game

457 familiarity and gender on the experience and learning metrics of participants were observed.

\subsection{Qualitative analysis}

460 The results from our qualitative analysis of the two open-ended survey questions are reported in

461 Tables 6 and 7 that follow. With respect to the first open-ended question, "How was your learning

462 experience using this tool?", almost $18 \%$ of participants reported that the tool was easy to use

463 while nearly $17 \%$ reported that the tool was difficult to use (Table 5). For example, two contrasting

464 participant comments are: "it was easy to navigate" and "I felt confused and overwhelmed on the

465 program almost the entire time I was using it...". Related to useability, almost $11 \%$ of participants

466 indicated that the controls for using the tool are not intuitive, e.g.: "it was very frustrating to try

467 and rotate the compass to the right spot...". Another $8 \%$ indicated that the tool had a high and

468 steep learning curve, e.g.: "firstly, I thought it is hard but then I got used to it". Furthermore, about

$46912.5 \%$ of participants had performance issues such as lagging and crashing, e.g.: "it was a little

470 slow, as it did not respond immediately to my inputs...".

471 Importantly, a little over $15 \%$ of participants reported that the tool has increased their interest in 472 learning the topic and $22 \%$ reported that they perceived the tool as effective for learning, while 473 only $6 \%$ reported that they did not perceive the tool to be effective for learning. For example, two 474 contrasting participant comments about the experience are: “...I felt like I was doing actual 475 work..." and "...I think that an in-person experience would be more effective to understand strike 
476 and dip...". Related to the latter example, $11 \%$ of participants indicated that they would prefer the 477 real environment to the virtual for learning about this topic.

478 Finally, our results show that $49 \%$ of the sampled population had an overall positive impression 479 of the tool whereas only $17 \%$ and $13 \%$ reported an overall negative or overall mixed impression, 480 respectively. Others did not express clear inclination.

481 A chi-square test of independence revealed that participants with low geographical software 482 familiarity had a much higher overall negative impression (29.5\%) compared to those with a high 483 geographical software familiarity $(2.85 \%), \chi^{2}(1, \mathrm{~N}=79)=9.52, \mathrm{p}<0.01$. The post-hoc test with 484 Bonferroni correction was in agreement that negative impressions are significantly more common 485 for participants in the low geographical software familiarity category $(p<0.01)$. No other 486 significant differences between the geographical software familiarity categories or game 487 familiarity categories were observed. 
489 With respect to the second question, "How did your experience ... change between ... mapping 490 activities?", $62.5 \%$ of participants reported that their experience improved from the first to the 491 second mapping activity (Table 6). More than half of those who reported an improvement to their 492 experience explicitly mentioned that their experience was easier in the second mapping activity 493 because of practicing in the first mapping activity. About $20 \%$ of participants reported that their 494 experience remained the same, and $18 \%$ reported that their experience worsened from the first to 495 the second mapping activity. From those who reported that their experience worsened, 12.4\% 496 stated that the second mapping activity was more difficult and almost $8 \%$ stated that they 497 experienced more lag in the second mapping activity. A chi-square test of independence revealed 498 no significant differences between geographical software familiarity categories or gaming 499 familiarity categories and the codes. In summary, the qualitative analysis of the second question 500 indicates that more exposure to the $\mathrm{SaD}$ tool improves the overall experience for users but the fact 501 that second activity is more demanding in terms of required graphic power resulted in more 502 performance issues. 
https://doi.org/10.5194/gc-2021-16

Preprint. Discussion started: 28 June 2021

(c) Author(s) 2021. CC BY 4.0 License. 


\section{DISCUSSION AND CONCLUSIONS}

506 Using the $\mathrm{SaD}$ tool, an entirely remote introductory field mapping exercise was successfully 507 completed by students during the COVID-19 pandemic. This field mapping exercise replicated 508 exactly, in the digital world, the tasks the students would have normally completed in an in-person 509 lab: measuring strike and dip of staged "outcrops", using those data to assemble a map, and 510 interpreting the geologic history for that "region". Using traditional aspects in a new way, this 511 environment not only taught students how to visualize the orientation of strike and dip on a rock 512 plane, but also how to correctly line up a compass using the RHR convention. It also challenged 513 students to conceptualize and infer overall geologic relationships using the measurements they 514 took at each individual 3D outcrop model. From a teaching perspective, the $\mathrm{SaD}$ tool also provides 515 three distinct advantages: 1) the time required to set up a staged beginner mapping area is 516 conserved, which in turn permits 2) multiple mapping environments to be explored by the students 517 (e.g. "practice” Map 1 followed by "real” Map 2) with different levels of challenge (e.g. bumper 518 cubes vs bumper rocks) available to facilitate individualized learning; as well as 3) the bumper 519 setting flagging incorrect measurements, providing the opportunity for self-correction. In a regular 520 face-to-face introductory mapping lab, there is realistically only time to set up one staged mapping environment and during the exercise, the instructor is trying to assist individual students with a wide range of issues from using their left hand, to holding the compass upside down, to having made and mapped several incorrect measurements without realizing their error. SaD dramatically increased efficient instruction through error flagging alone.

Both quantitative and qualitative results suggest that the students reacted overall positively to the $\mathrm{SaD}$ tool. Further, qualitative results suggest that $\mathrm{SaD}$ was an effective learning instrument for the

528 mapping exercise, as participants reported an increase in understanding of strike and dip from Map

5291 to Map 2. These findings are in agreement with those from the earlier pilot study $(\mathrm{n}=11)$ using 530 the same software (Bursztyn et al., 2021) and suggest that $\mathrm{SaD}$ can be considered an effective learning instrument. The quantitative results indicate that students familiar with other geographical software or gaming software had a much better experience in light of representational fidelity, immediacy of control, perceived usefulness, perceived ease of use, control and active learning, 
perceived learning effectiveness, satisfaction, and self-efficacy compared to those who were unfamiliar. This is important as it suggests that introducing students to virtual learning environments more frequently will have positive effects on their learning experience.

Although the results of the qualitative analysis are valuable on their own, when considering the prior individual experiences of users in relation to their open-ended feedback, interesting themes emerge. When comparing participants in the high geographical software familiarity group to those in the low geographical software familiarity group, we see that those in the high familiarity group perceived the tool to be much easier to use and controls to be more intuitive. Similarly, participants in the high familiarity group experienced less performance issues and had a less steep learning curve. It was also the case that participants in this group had a lower tendency to claim preference for the real environment over the virtual one and these participants determined the tool to be effective for learning at much higher rates than those in the low familiarity group. The high geographical software familiarity grouping reported a much higher overall positive impression and much lower overall negative impression of the tool. Finally, a very similar trend is seen when comparing participants of high and low gaming familiarity. Apart from performance issues and learning curve, in almost all the other metrics, participants in the high gaming familiarity group reported a much better experience than those in the low gaming familiarity group. The qualitative results align with the quantitative results, which further strengthens the conclusion that students with higher geographical software familiarity and to some degree, gaming familiarity, gained more cognitively and psychologically from their SaD experience. Our results corroborate observations made in other experiments evaluating the importance and impact of prior familiarity with similar software on the experiences and performance of learners in virtual environments (Bagher et al., under review). Importantly, the absence of effects of gender on the participants' experience and learning metrics suggests an equitable learning experience across gender demographics.

560 To further explore some of the feedback received through the open-ended questions, we address

561 comments geared towards issues with usability, fidelity to real world environments, and limitations 562 with software. 


\subsection{Usability and fidelity to learning mapping in the real world}

564 Notably, most of the negative comments with the $\mathrm{SaD}$ tool are with regard to lag and frustration

565 of becoming familiar with the settings and controls (Tables 5 and 6) and not the sometimes

566 confusing aspect of taking and interpreting strike and dip measurements. Within this lab, the 3D

567 virtual outcrops presented had easy to determine strike planes. Because the RHR convention was

568 represented with a digital right hand that could be manipulated, users could easily determine dip

569 direction and therefore angle. Furthermore, because participants were using the tool with the

570 beginner bumper setting, they were alerted to any incorrect measurements instantaneously.

571 In the field without a perfectly staged 3D outcrop, it is sometimes difficult to determine the true

572 strike of a lithologic unit, and therefore easy to accidentally measure an apparent plane instead of

573 a true one. Although no "lag" time is associated with field mapping (except perhaps prolonged

574 snack breaks), good, easily determinable strike and dip outcrops are not always abundant. This

575 forces introductory students to learn and practice strike and dip on outcrops that are overly

576 complicated for new learners. For example, Appalachian State students must travel one to two

577 hours each way to the Valley and Ridge Province where they learn how to map in "sedimentary"

578 units that are, in reality, slightly metamorphosed meta-sedimentary rocks, and sometimes have

579 slight foliation or crystallization. Furthermore, the region is heavily deformed with outcrop-

580 regional sized folds and faults. Finding appropriate outcrops for introductory students is difficult

581 and those that are found are on steep terrain and therefore not wholly accessible.

582 Interestingly enough, most of the comments made about the reactiveness of the controls are 583 variations of comments heard as an instructor from students in the field. For example, "Initially I 584 didn't know how to use it, so it was frustrating...." and “...At first it was a bit overwhelming, but 585 with some instruction it became much easier and quicker to use...". This is a common comment 586 from students at the end of the semester in a field methods course. Another comment, "It was very 587 frustrating to try and rotate the compass to the right spot..." or "...I struggled with getting 588 everything in place each time...", is a staple in regards to placing the compass when students first 589 get into the field. The comment regarding only seeing one strike and dip measurement at a time 590 (“...was not effective in learning because I was only able to see one strike dip at a time and could 591 not figure out how they related to each other spatially...") is also not an uncommon struggle in the 
field. Most places do not have kilometer long outcrops in which to visualize the structures of the whole area. One must actively map each individual strike and dip measurement one at a time, only interpreting the structures once there are enough points across the map to put together the geologic story. Similarly, SaD users may also view their "map" with the World Map feature (Fig. 2c) and visualize the region in its entirety. Lastly, the comment "I felt confused and overwhelmed on the program almost the entire time I was using it" is so common in the field that many instructors address this as a known occurrence and the statement is frequently countered with some version of 'You may be lost the majority of the time, the key is to recognize when you are "found" and to fill in the gaps.'

601 Despite the participants in this study having never actually mapped geology before, let alone in a 602 real-world environment, there were several confident comments that in person experience would 603 be more effective for learning and alleviating confusion than the $\mathrm{SaD}$ tool. These comments are 604 difficult to address with their "the grass is always greener" perspective. This type of perspective was seen in a study by Stumpf et al., (2008), who found that students exposed to an in-person only

606 field trip claimed preference for the virtual version while students in the virtual field trip group decreed the opposite.

608

609 The thought that nothing can compare with a real-world field trip is predominant among some 610 geologists but it is one that is exclusive and unimaginative. With the development of realistic 611 virtual desktop environments and iVR experiences, along with public access to texture and 612 material designers like Substance by Adobe, it is becoming more possible and pertinent to develop 613 virtual environments that mimic real world structures, and therefore their value for replicating 614 place- or discovery-based learning (e.g. O'Connor and Domingo, 2017; Atit et al., 2020; Parong 615 and Mayer, 2020; Wu et al., 2020). With iVR, users can even navigate through and interact with 616 virtual environments in a very realistic way, which we suggest is also valuable in discovery-based 617 learning (e.g. Liu et al., 2020; Parong and Mayer, 2020; Wu et al., 2020).

618 The results of this study point to a mix of positive evaluation and room for improvements of the $619 \mathrm{SaD}$ tool. Considering that $\mathrm{SaD}$ is still evolving, it is expected to receive comments related to 620 usability issues from the participants. Such comments can help us better identify the shortcomings 621 of this tool and plan for future improvements. It is important to emphasize that our results also 
indicate that a high number of participants perceived the tool as useful for their learning and the overall impression of the tool is positive.

624

625

626

627

\subsection{Limitations and future work}

\subsubsection{Procedural limitations}

For this study, $\mathrm{SaD}$ was used in a single lab session following an earlier workbook-style mapping exercise. Although all students were assigned the earlier mapping exercise, only those who completed it had it returned and available for their reference during the subsequent $\mathrm{SaD}$ lab activity. Furthermore, it is unclear how many students, if any, referred back to this exercise for reminders or guidance during the $\mathrm{SaD}$ exercise. Because the $\mathrm{SaD}$ lab was administered during a single lab session, Map 1 (the practice map) was made optional to alleviate the pressure of potential time constraints. Consequently, not all students completed the practice map prior to the main assignment (Map 2). The small-scale pilot study (Bursztyn et al., 2021) built in two work and submission sessions to the exercise with instructor feedback following the first "practice" mapping activity. We were unable to follow this procedure due to curriculum scheduling complications for the present study and this limitation resulted in students either opting to not complete the first mapping exercise, or completing both with the pressure of time-constraints.

Within the dVR experience itself, participants were limited to using the $\mathrm{SaD}$ tool restricted to the beginner bumper cubes setting. With bumper cubes incorrect measurements are flagged, but students do not know why they are wrong or how to correct themselves. It will be important to develop the $\mathrm{SaD}$ tool to include adaptive interventions such as individualized embedded hints and mapping guidance that would facilitate the learning experience of beginner mappers using the bumper settings. In VR environments it is feasible to implement adaptive learning strategies, such as adaptive interventions, hints, and feedback (Peirce and Wade, 2010; Zaharias et al., 2012), in addition to more dynamic strategies in the form of difficulty and learning content adjustments within the learning experience (Hocine et al., 2015; Streicher and Smeddinck, 2016). Such strategies can support personalized experiences for learners exhibiting different levels of abilities and competencies in relation to the learning experience. In the case of our bumper settings, 
651 adaptive interventions might provide feedback on the nature of the error the user has made. It will also be important to study the effect of including such adaptive interventions into the learning environment, both on student learning and on user experience.

Finally, from an individual differences perspective, the exclusion of ethnicity from the participant questionnaire survey was an oversight not realized until too late in the procedure to be corrected. Critically examining individual differences in the context of the learning experience will continue to be of utmost importance moving forward. Furthermore, in this study, we did not collect the scores from the student work. Individual differences are not only important to consider for the useability of the instrument, but also critical to examine the effect the tool has on student learning.

\subsubsection{Technical limitations}

663 Several students experienced technical difficulties including their computers crashing, the SaD 664 tool lagging, and difficulty maneuvering within the virtual environment. Between the pilot study 665 (Bursztyn et al., 2021) and this study we tried to address the lagging concern, knowing that many 666 students would not have access to gaming computers with high-powered video cards. Visual lag 667 can be reduced by minimizing the complexity of the 3D rock models through reducing the number 668 of polygons for each 3D model. However, the tradeoff in this regard is that the 3D models with 669 reduced polygons will at some point become no longer recognizable as particular rock types. We 670 have since been exploring other avenues such as applying detailed texture maps over simplified 671 geometries. Through the use of programs such as Adobe Substance highly detailed textures can be 672 created that give the appearance of complex 3D geometry, many of which are digital twins for 673 diagnostic rock textures. These textures can then be applied to 3D models with simple geometry

674 (such as cubes) while retaining the visual appearance and detail of highly complex 3D models but 675 without creating lag.

5 Outlook: Advancing inclusivity, accessibility, and realism

677 Beyond the students' technical difficulties, we also recognize that the interaction fidelity of 678 maneuvering in a two-dimensional dVR environment representing a complex 3D natural 679 environment is limited. Navigation within such an environment is complex and requires training 
680 (key combinations, mouse and/or trackpad to maneuver and position the compass vs walking up 681 to a surface and using one's hands). On the other hand, it has been shown that virtual environments, 682 especially developed for web-based distribution and mobile devices, can remove barriers to 683 accessibility and create a culture of inclusion in geoscience classrooms (O'Sullivan and Kearney, 684 2018; Chenrai and Jitmahantakul, 2019). We believe that with immersive VR technology 685 becoming widely accessible, we can achieve both: accessibility and natural interactivity. 686 Immersive VR offers 3D-in-3D interfaces which are ideal for representing the 3D data of 687 geological structures as well as realizing the 3D interactions of measuring them (e.g., positioning 688 a compass on a planar surface). The iVR interface of $\mathrm{SaD}$ has been developed this spring and we 689 intend to leverage this version of the tool to evaluate place-based learning and 3D interactions within that environment in the coming fall semester. Research on virtual learning environments has shown that the immersive, interactive, and 3D nature of iVR can potentially reduce the performance gap between students with high and low spatial abilities (Simpson et al., 2017; Lages and Bowman, 2018) which have been shown critical for STEM education (Newcombe, 2010). Immersive 3D visualizations can demonstrate the extent of landscapes and geological features in a form that is beneficial for students to develop spatial thinking, since they closely mirror everyday perceptual experience (Simpson, 2020). This mirroring capability is important in the context of the current study where students expressed preference for a more real-world experience. In addition, current iVR technology allows for the integration of high-fidelity perceptual information (e.g., position, orientation, shape, size, or motion) and additional abstract information (e.g., video, graphs, and text) into a single virtual environment, which would enable the teaching of complex geological concepts through understandable visual demonstrations (Bowman et al., 2003). Such explicit graphical presentations might act as a "cognitive prosthetic" for students with lower spatial ability (Mayer and Sims, 1994; Höffler and Leutner, 2011; Jamieson et al., 2014; Zhao et al., 2020); that is, low ability learners could gain a particular benefit from accessing an information-rich iVR environment as they have difficulty mentally constructing their own representation when learning about geological features

708 and processes from the textbook or a traditional field trip alone. This is also important for the 709 present study as it has been shown that low spatial ability learners can benefit more from a desktop VR application in comparison with high spatial ability learners (Lee et al., 2009). Future empirical 
711 evaluations of $\mathrm{SaD}$ comparing immersive versus non-immersive instances will include a stronger

712 focus on spatial abilities.

713

714 The $\mathrm{SaD}$ tool continues to be developed and evolve with each iteration into becoming a more

715 realistic digital twin for teaching field geology technique. The next steps for this tool are mapped

716 out, focused on creating 3D models that mirror real world lithologic features (including, but not

717 limited to, individual sand grains, identifiable fossils, foliation and crystalline textures). As a

718 community, we are ever closer to creating complete, realistic virtual environments for an inclusive

719 and accessible geology field class with world class "outcrops" that mimic those one sees in the

720 classic geology field camps and trips hosted in the Western United States. 
Appendix A: Full survey of questions asked to students participating in the SaD study Section A: Questionnaire

We would like to learn about your background and previous experience as it is relevant to this study. We have a few questions we would like your honest answers to. After that, we would ask about your experience with the web application used to explore the maps.

A1. Please enter your school email address. (i.e name@psu.edu)

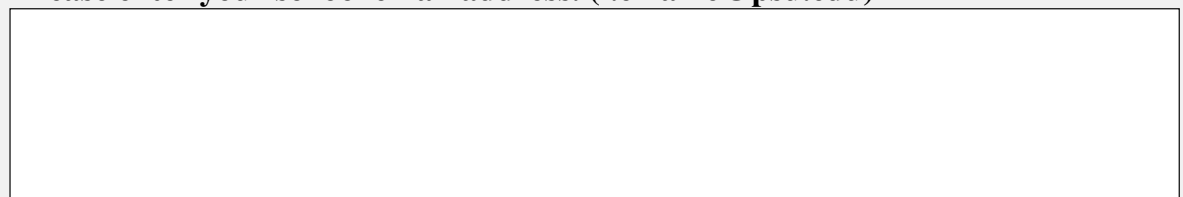

A2. By reviewing the consent form, I agree to take part in the study AND I am at least 18 years old (the collected data is anonymized).

Yes, I would like to participate in the study

No, I only do this exercise as a class assignment

A3. What is your age?

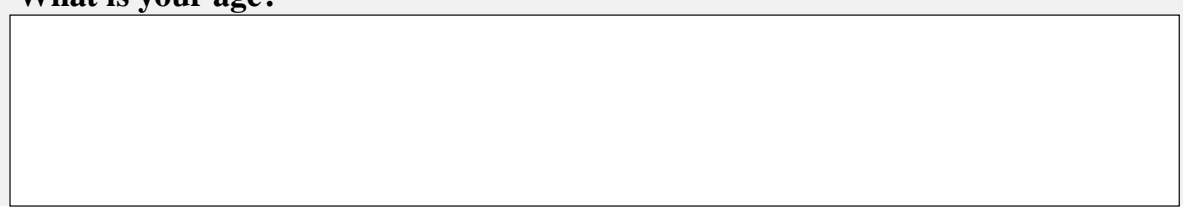

A4. To which gender identity do you most identify?

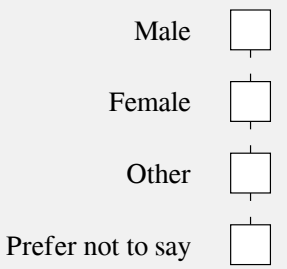

A5. What are your major and minor fields of study?

A6. What year of study are you in?

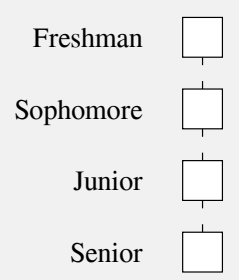


A7. How familiar are you navigating in geographical softwares such as ArcGIS, for instance, zoom in or dragging the map?

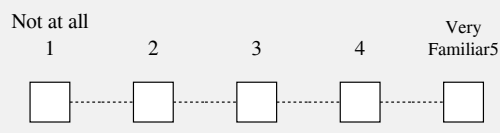

A8. How familiar are you with video games of any kind (gaming consoles, PC, or on phones)?

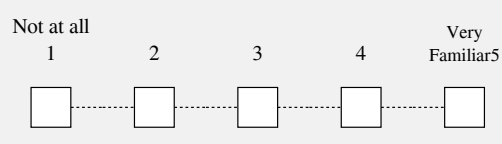

A9. Please rate the following questions from 1 (Strongly Disagree) to 5 (Strongly Agree).

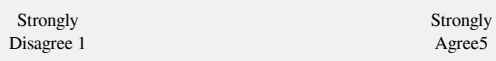

The realism of the mapping environment models motivates me to

$$
\text { learn }
$$

The realism of the mapping environment models helps to enhance

A10. Please rate the following questions from 1 (Strongly Disagree) to 5

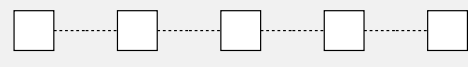

\section{my understanding}

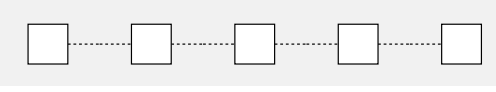

\section{(Strongly Agree). \\ The ability to change the view position of the 3-D objects allows
me to learn better \\ The ability to change the view position of the 3-D objects makes \\ learning more motivating and interesting
The ability to manipulate the objects within the virtual
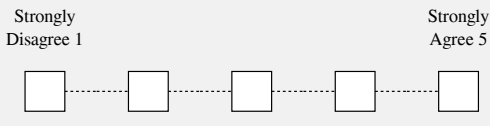 environment makes learning more motivating and interesting \\ The ability to manipulate the objects in real time helps to enhance my understanding
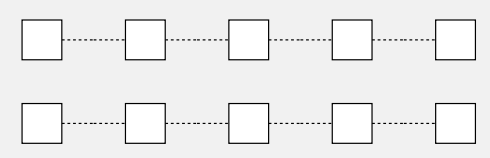

A11. Please rate the following questions from 1 (Strongly Disagree) to 5 (Strongly Agree).

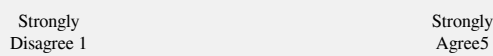

Using this type of computer program as a tool for learning in classroom increase/will increase my learning and academic

performance

Using this type of computer program enhances/will enhance the effectiveness on my learning

This type of computer program allows/will allow me to progress at my own pace

This type of computer program is useful in supporting my learning
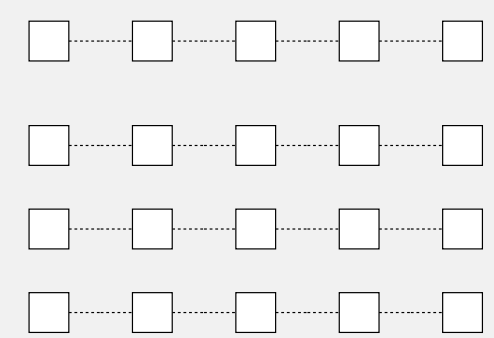
https://doi.org/10.5194/gc-2021-16

Preprint. Discussion started: 28 June 2021

(c) Author(s) 2021. CC BY 4.0 License.

A12. Please rate the following questions from 1 (Strongly Disagree) to 5 (Strongly Agree).

Learning to operate this type of computer program is easy for me

Learning how to use this type of computer program as an assignment is too complicated and difficult for me
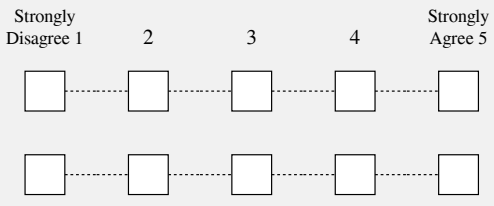

It is easy for me to find information in this computer program

Overall, I think this type of computer program is easy to use

A13. Please rate the following questions from 1 (Strongly Disagree) to 5

(Strongly Agree).

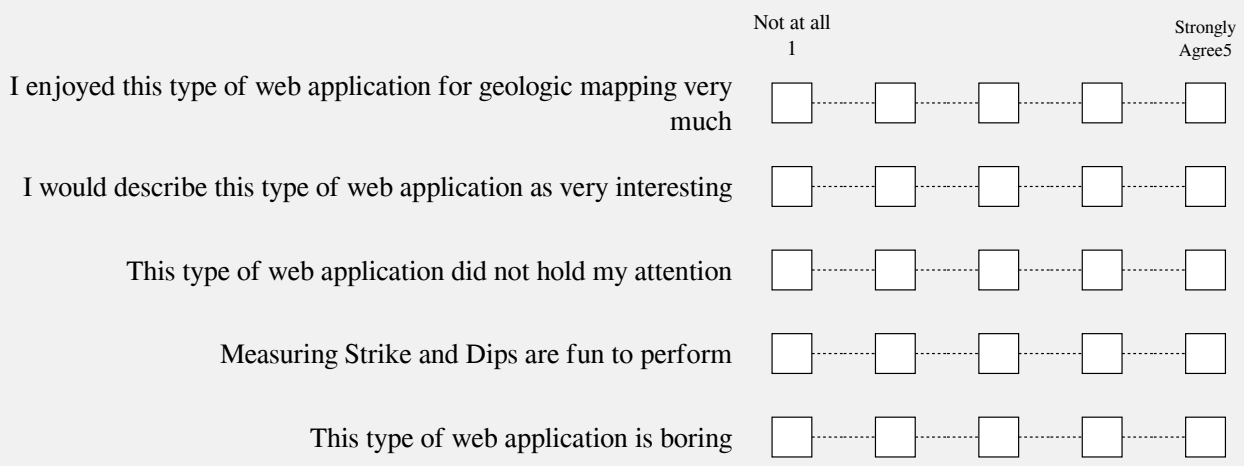

A14. Please rate the following questions from 1 (Strongly Disagree) to 5 (Strongly Agree).

This type of web application allows me to be more responsive and active in the learning process

This type of web application allows me to have more control over my own learning

This type of web application promotes self-paced learning

This type of web application helps to get myself engaged in the learning activity

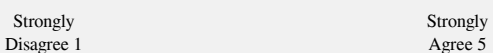
Agree 5
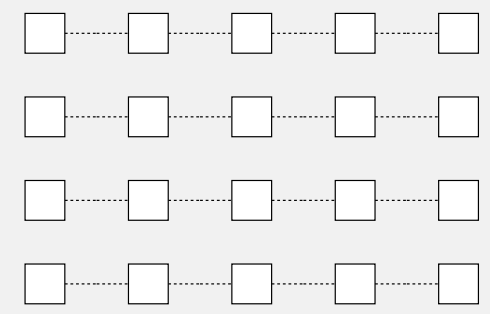

A15. Please rate the following questions from 1 (Strongly Disagree) to 5 (Strongly Agree).

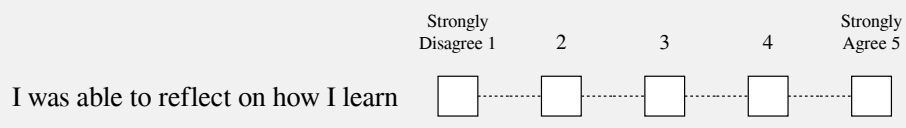

I was able to link new knowledge with my previous knowledge and experiences

I was able to become a better learner I was able to reflect on my own understanding 


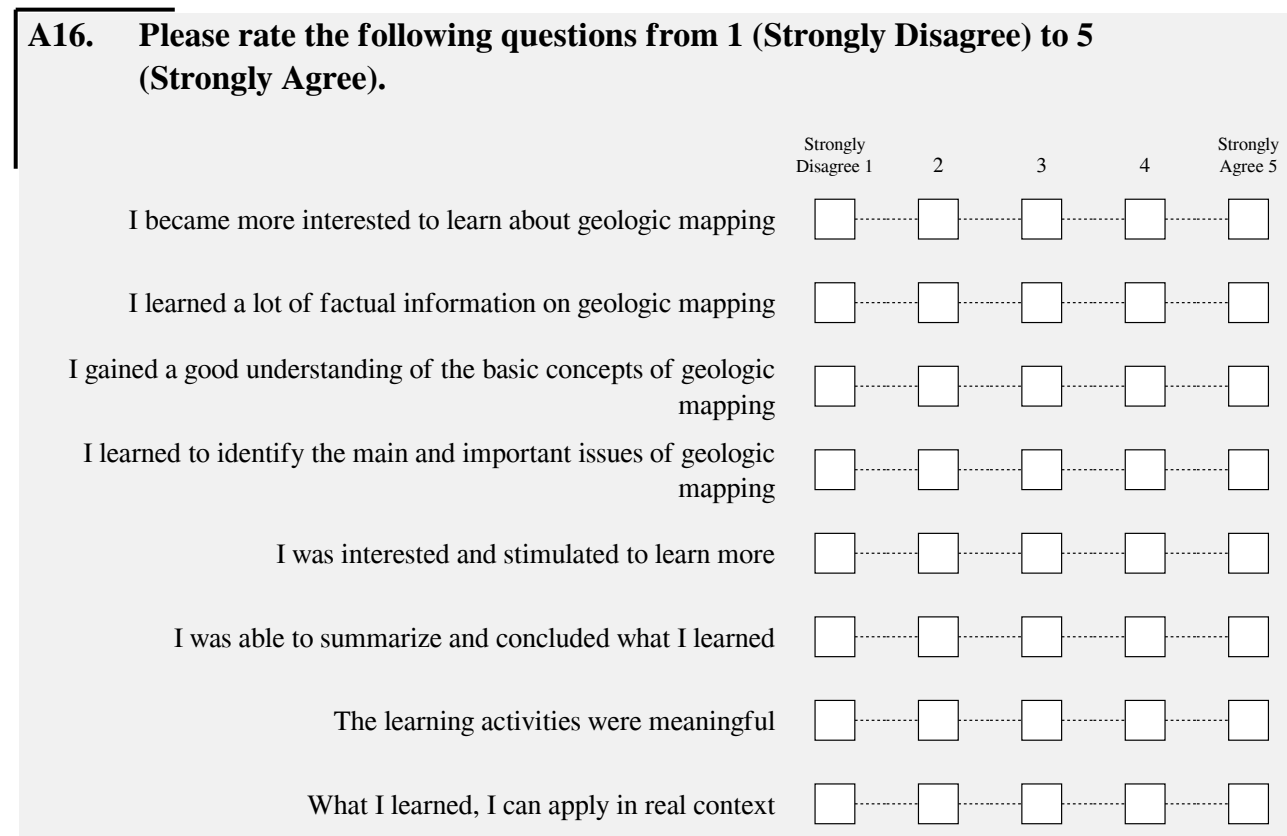

A17. Please rate the following questions from 1 (Strongly Disagree) to 5 (Strongly Agree).

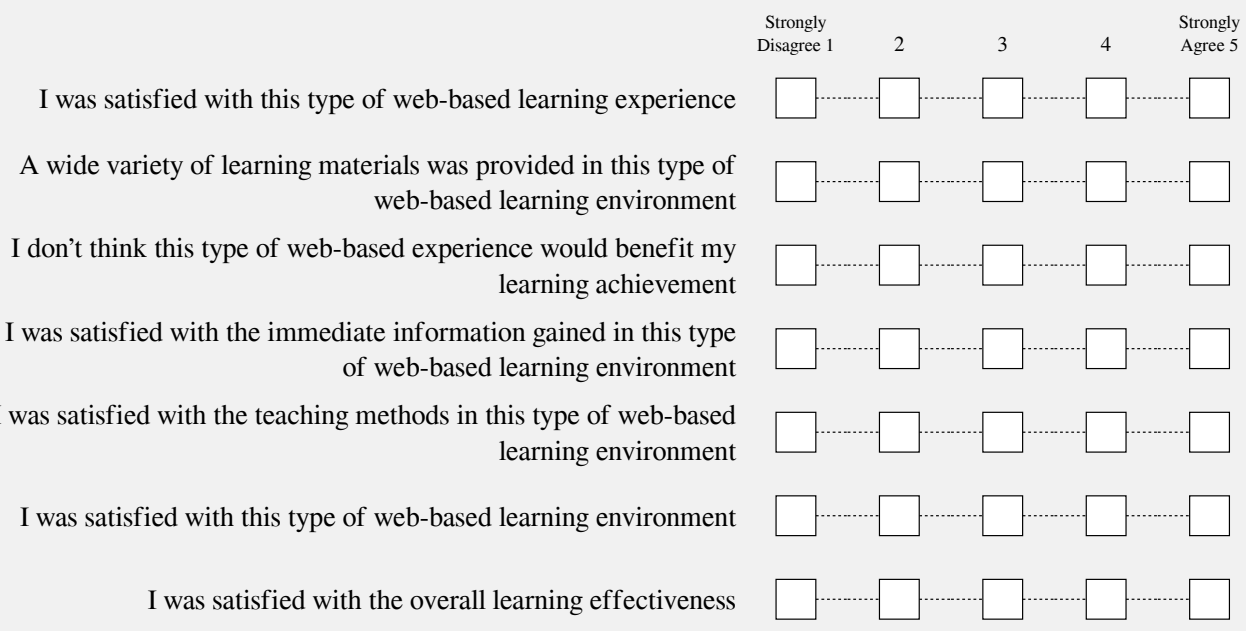

A18. Please rate the following questions from 1 (Strongly Disagree) to 5 (Strongly Agree).

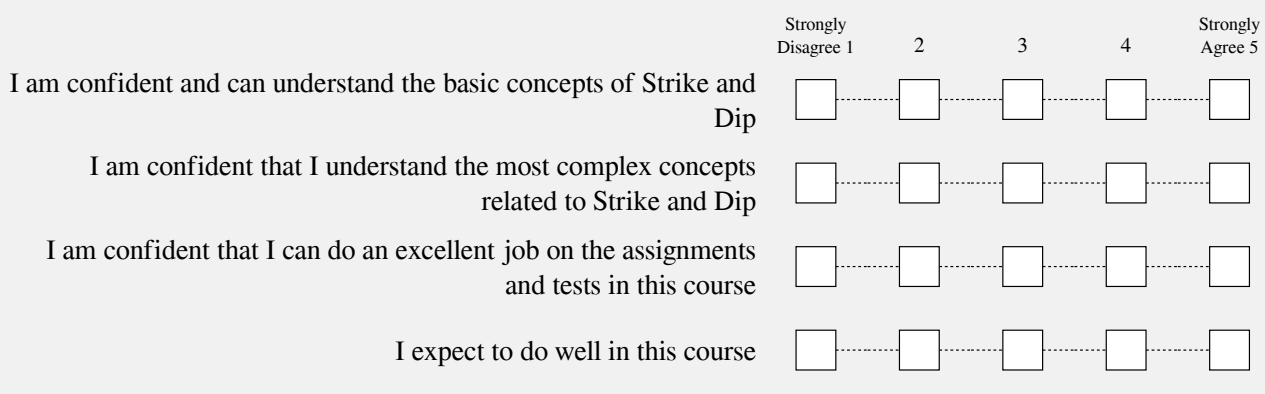




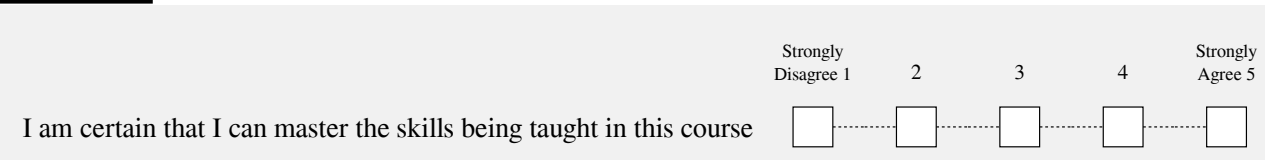

A19. How did your experience using the strike and dip tool change between the first and second mapping activities? Explain within the context of the technology (ease of use, functionality, etc.)

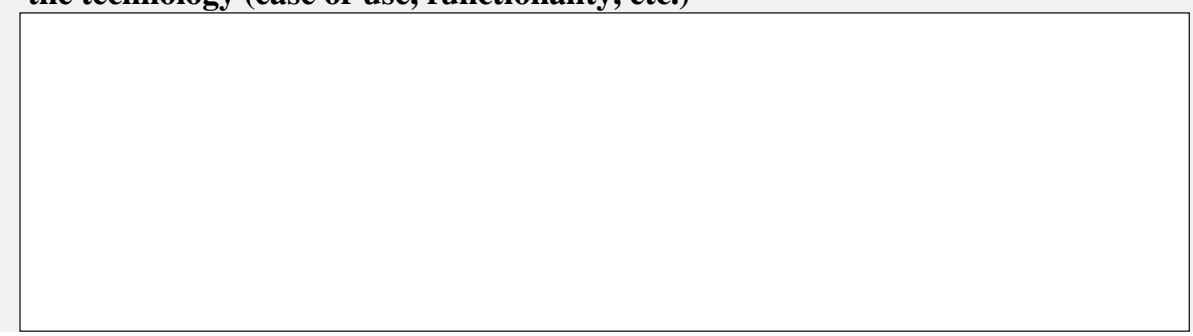

A20. How was your learning experience using this tool? Describe how you felt about practicing geologic mapping in a virtual environment.

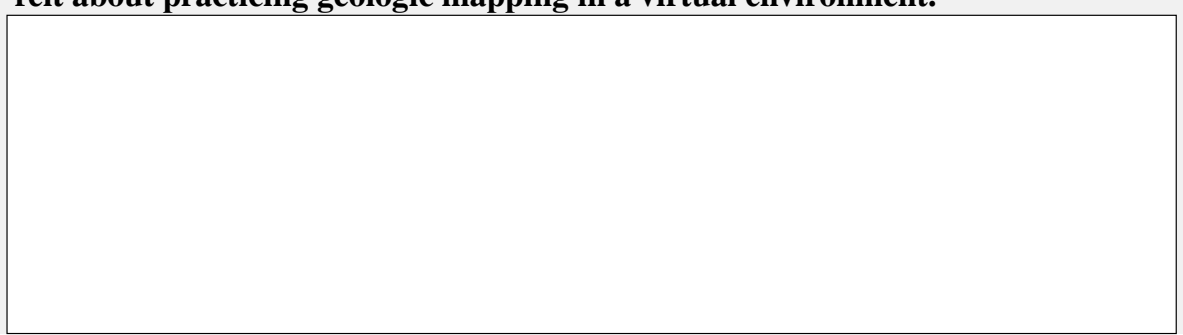

Section B: End of the assignment

Please press "SUBMIT" below. Have a good day!

B1. Thank you! This is the end of the experiment. We appreciate that you took the time to help us with our research. Would you like to participate in future studies?

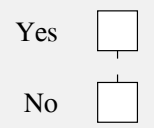

This is the end. 
723 The $\mathrm{SaD}$ tool is located at https://sites.psu.edu/virtualfieldtrips/strike-and-dip/. Additionally, a

724 developer log is located at https://sites.psu.edu/bartonmasters/sad-strike-and-dip-links/ and is

725 maintained by Bart Masters.

\section{AUTHOR CONTRIBUTIONS}

727 NB, HR and AK conceived the experiment in collaboration with PS and BM who developed and 728 programmed the SaD software. NB created the lab exercise. Analyses were conducted by PS, JH, 729 JZ and JOW in collaboration with AK. Manuscript was written by NB, PS, HR, AK, and JH. HR 730 created the figures. All authors discussed the results and manuscript narrative, and all contributed 731 substantially to the editing process.

\section{COMPETING INTERESTS}

733 The authors declare that they have no conflict of interest.

\section{SPECIAL ISSUE STATEMENT}

735 This article is part of the special issue "Virtual geoscience education resources" in Geoscience

736 Communication Letters.

\section{ACKNOWLEDGMENTS}

738 The authors would like to thank Dr. Peter La Femina of Penn State University and his teaching

739 assistants for performing this lab in his Geosc 001 - Physical Geology laboratory. We would also

740 like to thank Dr. Mahda Bagher for creating the survey used to gather the data used in this paper. 


\section{REFERENCES}

Alles, M., and Riggs, E. M.: Developing a process model for visual penetrative ability, in Feig. A.D., and Stokes, A., (Eds.), Qualitative Inquiry in Geoscience Education Research, Geological Society of America Special Paper 474, p. 63-80, 2011.

Almquist, H., Stanley, G., Blank, L., Hendrix, M., Rosenblatt, M., Hanfling, S., and Crews, J.: An Integrated Field-Based Approach to Building Teachers' Geoscience Skills, Journal of Geoscience Education, Vol. 59, No. 1, pp. 31-40, 2018.

Andrews, G. D., Labishak, G., Brown, S., Isom, S. L., Pettus, H. D., and Byers, T.,: Teaching with Digital 3D Models of Minerals and Rocks. GSA Today, Vol. 30, pp. 42-43, 2020.

Atit, K., Uttal, D. H., and Stieff, M., Situating space: using a discipline-focused lens to examine spatial thinking skills, Cognitive research: principles and implications, Vol. 5, No. 1, p. 19, 2020.

Bagher, M., Sajjadi, P., Wallgrün, J.O., La Femina, P.C., Klippel, A., under review. Move The Object or Move The User: The Role of Interaction Techniques on Embodied Learning in VR. Frontiers in Virtual Reality, 2021.

Bangera, G., and Brownell, S. E.: Course-based undergraduate research experiences can make scientific research more inclusive, CBE Life Sciences Education, Vol. 13, No. 4, pp. 602 606, 2014.

Barab, S. and Dede, C.: Games and Immersive Participatory Simulations for Science Education: An Emerging Type of Curricula, Journal of Science Education and Technology, Vol. 16, No. 1, pp. 1-3, 2007.

Bethune, K.: Changing Trends and Rethinking Geoscience Education in the Context of a Global Crisis. Geoscience Canada, Vol. 47, No. 4, pp. 167-169, https://doi.org/10.12789/geocanj.2020.47.164, 2020.

Bowman, D. A., North, C., Chen, J., Polys, N. F., Pyla, P. S., and Yilmaz, U.: Information-rich virtual environments, Proceedings of the ACM Symposium on Virtual Reality Software and Technology, ACM, New York, NY, p. 81., 2003.

Bowman, D. A. and McMahan, R. P.: Virtual reality: How much immersion is enough?, Computer, Vol. 40, No. 7, pp. 36-43, 2007. 
Bursztyn, N., Shelton, B., Walker, A., and Pederson, J.: Increasing Undergraduate Interest to Learn Geoscience with GPS-based Augmented Reality Field Trips on Students' Own Smartphones, GSA Today, pp. 4-10, 2017.

Bursztyn, N., Riegel, H., Sajjadi, P., Masters, B., Zhao, J., Huang, J., Bagher, M., Wallgrun, J., and Klippel, A. Fostering Geological Thinking Through Virtual Strike and Dip Measurements. 2021 IEEE Conference on Virtual Reality and 3D User Interfaces Abstracts and Workshops (VRW), pp. 303-308, doi: 10.1109/VRW52623.2021.00061, 2021.

Cawood, A. J., and Bond, C. E.: eRock: An Open-Access Repository of Virtual Outcrops for Geoscience Education, GSA Today, https://doi.org/10.1130/GSATG373GW.1, 2018.

Chenrai, P., and Jitmahantakul, S.: Applying Virtual Reality Technology to Geoscience Classrooms, Review of International Geographical Education Online, Vol. 9, No. 3, pp 577-590, 2019.

Cunningham, T.D., and Lansiquot, R.D.: Modeling Interdisciplinary Place-Based Learning in Virtual Worlds: Lessons Learned and Suggestions for the Future", in Lansiquot, R.D., and MacDonald S.P. (Eds.), Interdisciplinary Perspectives on Virtual Place-Based Learning, Springer International Publishing, Cham, pp. 133-145, 2019.

Dalgarno, B.: The potential of 3D virtual learning environments: A constructivist analysis. Electronic Journal of Instructional Science and Technology, Vol. 5, No. 2, pp. 3-6, 2002.

Dede, C.: Immersive interfaces for engagement and learning, Science, Vol. 323, No. 5910, pp. 6669, 2009.

Dolphin, G., Dutchak, A., Karchewski, B., and Cooper, J.: Virtual field experiences in introductory geology: Addressing a capacity problem, but finding a pedagogical one, Journal of Geoscience Education, Vol. 67, No. 2, pp. 114-130, 2019.

Earth Educators Rendezvous workshop, The whys and hows of implementing virtual and augmented reality in Earth Science Classrooms, conveners: Moysey, S., Maas, B., Lazar, K., Klippel, A., and Bursztyn, N., July 13-17, 2020.

Elkins, J., and Elkins, N. M. L.: Teaching geology in the field: Significant geoscience concept gains in entirely field-based introductory geology courses, Journal of Geoscience Education, Vol. 55, No. 2, 2017. 
Gagnier, K. M., Atit, K., Ormand, C. J., Shipley, T. F.: Comprehending 3D Diagrams: Sketching to Support Spatial Reasoning, Topics in Cognitive Science, Vol. 9, No. 4, pp. 883-901, 2017.

Giles, S., Jackson, C., and Stephen, N.: Barriers to fieldwork in undergraduate geoscience degrees, Nature Reviews Earth \& Environment, Vol. 1, No. 2, pp. 77-78, 2020.

Hall, T., Healey, M., and Harrison, M.: Fieldwork and disabled students: Discourses of exclusion and inclusion, Journal of Geography in Higher Education, Vol. 28, No. 2, pp. 255-280, 2004.

Hocine, N., Gouaich, A., and Cerri, S.A.: Dynamic Difficulty Adaptation in Serious Games for Motor Rehabilitation, International Conference on Serious Games, pp. 115-128, 2015.

Höffler, T.N., and Leutner, D.: The role of spatial ability in learning from instructional animations - Evidence for an ability-as-compensator hypothesis, Computers in Human Behavior, Vol. 27, No. 1, pp. 209-216, 2011.

IJsselsteijn, W.A., and Riva, G.: Being there: The experience of presence in mediated environments, in IJsselsteijn, W.A., Riva, G., and Davide, F., (Eds.), Being there: Concepts, effects and measurements of user presence in synthetic environments, IOS, Amsterdam, Oxford, pp. 3-16, 2003.

Jamieson, M., Cullen, B., McGee-Lennon, M., Brewster, S., and Evans, J. J.: The efficacy of cognitive prosthetic technology for people with memory impairments: a systematic review and meta-analysis, Neuropsychological rehabilitation, Vol. 24, No. 3-4, pp. 419-444, 2014.

Johnson-Glenberg, Mina C.: Immersive VR and Education. Embodied design principles that include gesture and hand controls. In Front. Robot. AI 5, p. 27. DOI: 10.3389/frobt.2018.00081, 2018.

Klingenberg, S., Jørgensen, M. L., Dandanell, G., Skriver, K., Mottelson, A., and Makransky, G.: Investigating the effect of teaching as a generative learning strategy when learning through desktop and immersive VR: A media and methods experiment. British Journal of Educational Technology, Vol. 51, No. 6, pp. 2115-2138, 2020.

Klippel, A., Zhao, J., Jackson, K. L., La Femina, P., Stubbs, C., and Oprean, D.: Transforming earth science education through immersive experiences - delivering on a long held promise. 

10.1177/0735633119854025, 2019.

Klippel, A., Zhao, J., Oprean, D., Wallgrün, J. O., Stubbs, C., La Femina, P., and Jackson, K. L.: The value of being there: toward a science of immersive virtual field trips. In Virtual Reality 24, pp. 753-770. DOI: 10.1007/s10055-019-00418-5, 2020.

Klippel, A., Zhao, J., Sajjadi, P., Wallgrün, J. O., Bagher, M. M., and Oprean, D.: Immersive placebased learning - An extended research framework. In : 2020 IEEE Conference on Virtual Reality and 3D User Interfaces Abstracts and Workshops (VRW). Piscataway, NJ: IEEE, pp. 449-454. Available online at https://conferences.computer.org/vrtvcg/2020/pdfs/VRW2020-4a2sylMzvhjhioY0A33wsS/653200a449/653200a449.pdf., 2020.

Kolb, David A.: Experiential learning. Experience as the source of learning and development. Second edition. Upper Saddle River, New Jersey: Pearson Education Inc., 2014.

Lages, W. S. and Bowman, D. A.: Move the Object or Move Myself?: Walking vs. Manipulation for the Examination of 3D Scientific Data, Frontiers in ICT, Vol. 5, p. 236., 2018.

Lansiquot, R. D. and MacDonald S. P. (Eds.): Interdisciplinary Perspectives on Virtual PlaceBased Learning, Springer International Publishing, Cham., 2019.

Lee, E.A.-L., Wong, K. W., and Fung, C. C.: Educational values of virtual reality: The case of spatial ability, Proceedings of World Academy of Science, Engineering and Technology. Paris, France, 2009.

Liu, R., Wang, L., Lei, J., Wang, Q., and Ren, Y.: Effects of an immersive virtual reality-based classroom on students' learning performance in science lessons, British Journal of Educational Technology, 2020.

Lopes, R., and Bidarra, R.: Adaptivity challenges in games and simulations: A survey, IEEE Transactions on Computational Intelligence and AI in Games, Vol. 3, No. 2, pp. 85-99, 2011.

Maceachren, A.M., and Brewer, I.: Developing a conceptual framework for visually-enabled geocollaboration, Int. J. Geographical Information Science, Vol. 18, No. 1, pp. 1-34, DOI: 10.1080/13658810310001596094, 2004. 
Marín-Spiotta, E., Barnes, R. T., Berhe, A. A., Hastings, M. G., Mattheis, A., Schneider, B., and Williams, B. M.: Hostile climates are barriers to diversifying the geosciences. In Adv. Geosci. 53, pp. 117-127. DOI: 10.5194/adgeo-53-117-2020, 2020.

Marshall, M. S. and Higley, M. C.: Multi-scale virtual field experience, Grand Ledge, Michigan, USA, Geosci. Commun. Discuss. [preprint], https://doi.org/10.5194/gc-2021-10, in review, 2021.

Mayer, R. E. and Sims, V. K.: For whom is a picture worth a thousand words? Extensions of a dual-coding theory of multimedia learning, Journal of Educational Psychology, Vol. 86, No. 3, pp. 389-401, 1994.

McComas W.F. (Ed.): The Language of Science Education: An Expanded Glossary of Key Terms and Concepts in Science Teaching and Learning, SensePublishers and Imprint: SensePublishers, Rotterda, 2014.

Mead, C., Buxner, S., Bruce, G., Taylor, W., Semken, S., and Anbar, A.D.: Immersive, interactive virtual field trips promote science learning, Journal of Geoscience Education, Vol. 67, No. 2, pp. 131-142. DOI: 10.1080/10899995.2019.1565285, 2019.

Morales, N., O’Connell, K. B., McNulty, S., Berkowitz, A., Bowser, G., Giamellaro, M., and Miriti, M. N.: Promoting inclusion in ecological field experiences: Examining and overcoming barriers to a professional rite of passage, The Bulletin of the Ecological Society of America, Vol. 101, No. 4, p. 11., 2020.

Moysey, S. M. J., and Lazar, K. B.: Using virtual reality as a tool for field-based learning in the earth sciences, in Lansiquot, R.D., and MacDonald, S.P. (Eds.), Interdisciplinary Perspectives on Virtual Place-Based Learning, Springer International Publishing, Cham., 2019.

Newcombe, N. S.: Picture This: Increasing math and science learning by improving spatial thinking, American Educator, 2010.

O'Connor, E.A. and Domingo, J.: A Practical Guide, With Theoretical Underpinnings, for Creating Effective Virtual Reality Learning Environments, Journal of Educational Technology Systems, Vol. 45, No. 3, pp. 343-364, 2017.

Orion, N., and Hofstein, A.: Factors that influence learning during a scientific field trip in a natural environment, Journal of Research in Science Teaching, Vol. 31, No. 10, pp. 1097-1119, 2014. 
Ormand, C. J., Shipley, T. F., Tikoff, B., Harwood, C. L., Atit, K., and Boone, A. P.: Evaluating Geoscience Students' Spatial Thinking Skills in a Multi-Institutional Classroom Study, Journal of Geoscience Education, Vol. 62, No. 1, pp. 146-154, 2014.

O’Sullivan, M., and Kearney, G.: Virtual Reality (VR) Technology: Empowering Managers to Reduce and Eliminate Accessibility Barriers for People with Autism Spectrum Disorders, Studies in Health Technology and Informatics, Vol. 256, pp. 253-261, 2018.

Parong, J., and Mayer, R. E.: Cognitive and affective processes for learning science in immersive virtual reality, Journal of Computer Assisted Learning, 2020.

Peirce, N., and Wade, V.: Personalised learning for casual games: The 'language trap' online language learning game, Leading Issues in Games Based Learning, Vol. 159, 2019.

Petersen, G. B., Klingenberg, S., Mayer, R. E., and Makransky, G.: The virtual field trip: Investigating how to optimize immersive virtual learning in climate change education. In Br J Educ Technol. DOI: 10.1111/bjet.12991, 2020.

Powers, A. L.: An evaluation of four place-based education programs, The Journal of Environmental Education, Vol. 35, No. 4, pp. 17-32, 2004.

President's Council of Advisors on Science and Technology (PCAST): Engage to Excel: Producing One Million Additional College Graduates with Degrees in Science, Technology, Engineering and Mathematics, U.S. Government Office of Science and Technology, Washington, DC, 2012.

Pyle, E. J.: The evaluation of field course experiences: A framework for development, improvement, and reporting, in Whitmeyer, S.J., Mogk, D.W., and Pyle, E.J. (Eds.), Field Geology Education: Historical perspectives and modern approaches: GSA Special Paper 461, Geological Society of America, Boulder, CO, pp. 341-356, 2009.

Rotzien, J. R., Sincavage, R., Pellowski, C., Gavillot, Y., Cooper, S., Shannon, J., Sawyer, J.F., Yildiz, U., Filkorn, H., and Uzunlar, N.: Field-based geoscience education during the COVID-19 pandemic: Planning and execution, Part II: Geological Society of America, GSA 2020 Connects Online, abstract no. 359659. https://doi.org/10.1130/abs/2020AM359659., 2020.

Rotzein, J. R., Sincavage, R., Pellowski, C., Gavillot, Y., Filkorn, Cooper, S., Shannon, J., Yildiz, U., Sawyer, F., and Uzunlar, N.: Field-Based Geoscience Education during the COVID-19 

doi.org/10.1130/GSATG483A.1. CC-BY-NC, 2021.

Sajjadi, P., van Broeckhoven, F., and de Troyer, O.: Dynamically adaptive educational games: A new perspective", International Conference on Serious Games, pp. 71-76, 2014

Sajjadi, P., Zhao, J., Wallgrün, J. O., Fatemi, A., Zidik, Z., La Femina, P., Fuhrman, T., and Klippel, A.: The effect of virtual agent gender and embodiment on the experiences and performance of students in Virtual Field Trips. In : 2020 IEEE International Conference on Engineering, Technology and Education. Piscataway, New Jersey: IEEE, pp. 1-8, 2020.

Schreier, M.: Qualitative content analysis in practice. Sage Publications, 2012.

Semken, S., Ward, E.G., Moosavi, S., and Chinn, P.W.U., 2018. Place-based education in geoscience: Theory, research, practice, and assessment: Theory, Research, Practice, and Assessment, Journal of Geoscience Education, Vol. 65, No. 4, pp. 542-562.

Shipley, T. F., Tikoff, B., Ormand, C., and Manduca, C.: Structural geology practice and learning, from the perspective of cognitive science, Journal of Structural Geology, Vol. 54, pp. 72 84, 2013.

Shute, V.J., Wang, L., Greiff, S., Zhao, W., and Moore, G.: Measuring problem solving skills via stealth assessment in an engaging video game, Computers in Human Behavior, Vol. 63, pp. 106-117, 2016.

Simpson, M., Zhao, J., and Klippel, A.: Take a walk: Evaluating movement types for data visualization in immersive virtual reality, Workshop on Immersive Analytics (IA), at IEEE VIS, Phoenix, Arizona, USA, October $1^{\text {st }}, 2017$.

Simpson, M.: Scale and Space: Representations in Immersive Virtual Reality, Ph.D., University Park, PA USA, 2020.

Slater, M.: Measuring Presence: A Response to the Witmer and Singer Presence Questionnaire, Presence: Teleoperators and Virtual Environments, Vol. 8, No. 5, pp. 560-565, 1999.

Streicher, A., and Smeddinck, J. D.: Personalized and Adaptive Serious Games, Entertainment Computing and Serious Games, pp. 332-377., 2016.

Stumpf II, R. J. ,Douglass, J., and Dorn, R. I.: Learning Desert Geomorphology Virtually versus in the Field, Journal of Geography in Higher Education, Vol. 32, No.3, pp. 387-399, DOI: 10.1080/03098260802221140, 2008. 
Tibaldi, A., Bonali, F. L., Vitello, F., Delage, E., Nomikou, P., Antoniou, V. E., Becciani, U., Van Wyk de Vreis, B., Krokos, M., and Whitworth, M.: Real world-based immersive Virtual Reality for research, teaching and communication in volcanology. Bull Volcanol. Vol. 82, No. 38, https://doi.org/10.1007/s00445-020-01376-6, 2020.

Titus, S., and Horsman, E.: Characterizing and Improving Spatial Visualization Skills", Journal of Geoscience Education, Vol. 57, No. 4, pp. 242-254, 2009.

Uttal, D.H. and Cohen, C.A.: Spatial Thinking and STEM Education, Vol. 57, pp. 147-181, 2012. Vandewaetere, M., Cornillie, F., Clarebout, G., and Desmet, P.: Adaptivity in Educational Games: Including Player and Gameplay Characteristics, International Journal of Higher Education, Vol. 2, No. 2, 2013.

Whitmeyer, S.J. and Dordevic, M.: Creating virtual geologic mapping exercises in a changing world. Geosphere 2020; Vol. 17, No.1, pp. 226-243, https://doi.org/10.1130/GES02308.1, 2021.

Winn, W.: A conceptual basis for educational applications of virtual reality. Technical Publication R-93-9, Human Interface Technology Laboratory of the Washington Technology Center, Seattle: University of Washington, 1993.

Witmer, B.G. and Singer, M.J.: Measuring presence in virtual environments: A presence questionnaire, Presence, Vol. 7, No. 3, pp. 225-240, 1998.

$\mathrm{Wu}, \mathrm{B} ., \mathrm{Yu}, \mathrm{X}$. , and $\mathrm{Gu}, \mathrm{X}$. : Effectiveness of immersive virtual reality using head-mounted displays on learning performance: A meta-analysis, British Journal of Educational Technology, Vo. 51, Iss. 6, pp. 1991-2005, https://doi.org/10.1111/bjet.13023, 2020.

Zaharias, P., Mehlenbacher, B., Law, E.L.-C., and Sun, X.: Evaluating user experience of adaptive digital educational games with Activity Theory, International Journal of Human-Computer Studies, Vol. 70, No. 7, pp. 478-497, 2012.

Zhao, J., and Klippel, A.: Scale-unexplored opportunities for immersive technologies in placebased learning, 2019 IEEE Conference on Virtual Reality and 3D User Interfaces (VR), pp. 155-162, 2019.

Zhao, J., Simpson, M., Wallgrün, J.O., Sajjadi, P., and Klippel, A.: Exploring the Effects of Geographic Scale on Spatial Learning, Cognitive research: principles and implications, Vol. 5, No. 1, p. 14, 2020. 